\title{
Biologisch-epidemiologische Gedanken über die Frage der Diphtherie- und Pseudodiphtheriebazillen, mit 'besonderer Berücksichtigung des Bacillus Hofmanni.
}

\author{
Von \\ Frl. M. van Riemsdyk, \\ Aseistentin am bygienisch-baktorjologischen Institut der Universitat Amsterdam.
}

\section{Einleitung.}

Keine Diphtheriebekämpfung ohne bakteriologische Hilfe und in manchẹn Fällen auch infolge des wenig einheitlichen klinischen Bildes keine richtige Diagnose des Diphtheriekranken ohne bakteriologische Untersuchung; dies hat sich wohl seit der Entdeckung des Diphtheriebacillus durch Löffler mehr und mehr bewährt, und jetzt gibt es wohI kaum noch jemand, der damit nicht vöIlig einverstanden ist.

Obwohl man, dank der eifrigen Erforschung der- epidemiologischen Verhältnisse bei dieser Krankheit und der von Behringschen Antitoxintherapie, sagen kann, daß es keine so furchtbaren Epidemien mehr gibt wie früher, wo unter den Kindern wahre Verwüstungen angerichtèt wurden, und, wenn es jetzt noch zur Epidemie kommt, die Mortalität unendlich herabgesunken ist, so kann man doch keineswegs sagen, daß die Krankheit. erloschen ist. Sie besteht noch ebenso wie früher in all ihrer Heftigkeit, nur mit dem Unterschiede, daß sie jetzt, dank der streng spezifischen antidiphtherischen Therapie und der wirksamen hygienischen Maßnahmen, in ihrem freien Lauf gehemmt und an gewisse Schranken gebunden wird.

Die Diphtherie ist eine Krankheit, welche man noch immer unter die konstant vorkommenden Kinderkrankheiten zu rechnen hat, die fast überall in Europa endemisch auftritt und dann und wann unter günstigen Verhältnissen zur Epidemie aufflackern kann.

Selbstverständlich ist es denn auch, daß die bakteriologische Diphtheriediagnostik für den medizinischen Bakteriologen zu den am meisten vorkommenden Untersuchungen gehört und vielleicht auch eine von den 
schwersten Untersuchungen ist, nicht was die Technik, sondern vielmehr was die richtige Einsicht in die Frage des Diphtherie- und Pseudodiphtheriebacillus anbelangt. Schon von Loefflers Entdeckung an ist das eben die wichtige Frage gewesen, über die so unendlich viel geschrieben und diskutiert worden ist. Die 7. Tagung der Freien Vereinigung für Mikrobiologie in Berlin 1913 hat davon von neuem den Beweis geliefert, und man fragt sich wohl, wird es denn nie zu einer Lösung kommen?

Jedermann, der sich mit der bakteriologischen Untersuchung von Diphtherie im weitesten Sinne des Wortes beschäftigt, weiß aus Erfahrung, welche große Schwierigkeiten eben die Gruppe der sogenannten Pseudodiphtheriebazillen dabei bietet und jene Untersuchung fast zu einer unmöglichen macht, wenn man über diese Frage nicht zur völligen Klarheit gekommen ist.

Die Gruppe der sogenannten Pseudodiphtheriebazillen (Bacillus diphtheroides) ist eine überaus große. Man hat sie auf den verschiedensten gesunden und pathologisch veränderten Schleimhäuten, in Abszessen, auf der Haut, in den Sekreten und Exkreten des Menschen, bei Geflügel (Hühnern, Tauben), Ratten, Hunden, in Vaccinelymphe, Milch usw. gefunden. Verschiedene Arten sind beschrieben worden, z. B. Bac. ceruminis, Bac. auris, Bac. coryzae segmentosus, Bac. diphtheroides citreus; Bac. diphtheroides liquefaciens, Corynebacterium vaccinale usw. usw, aber diese Organismen unterscheiden sich kulturell und morphologisch so stark, daß man sie höchstens zu der Gruppe der diphtheroiden Bazillen, wenn man will zu der Gruppe der Corynebakterien (Lehmann und Neumann) oder der noch viel mehr umfassenden Gruppe der Mycobacteriaceae (de Negri) rechnen kann. In einer mehr einheitlichen Gruppe kann man sie kaum mehr unterbringen. Obwohl man fast sagen könnte, daß es kaum eine Stelle am menschlichen Körper gibt, wo nicht einmal Pscudodiphtheriebazillen gefunden sind, gibt es doch nur zwei Schleimhäute, wo sie konstant angetroffen werden, nämlich die der Nasen-Rachenhöhle (Bac. Hofmanni) und des Konjunktivalsacks (Bac. Xerosis).

Diese zwei diphtherieähnlichen Bazillengruppen täuschen morphologisch und kulturell den echten Diphtheriebacillus so vor, daß man sie wohl zu den echten Pseudodiphtheriebazillen rechnen darf. Sie geben auch zwei viel einheitlichere Gruppen als die erstgenannten. Morphologisch und kulturell sind die Unterschiede von den verschiedenen Stämmen untereinander auf ziemlich enge Grenzen zurückzuführen; nur agglutinatorisch verhalten sie sich nicht so einheitlich, wie man das bei den mehr parasitär lebenden Organismen beobachtet. Man wird sich ihnen gegenïberstellen wie den Bact. coli, Bac. paratyphi B, Bac. faccalis alkali- 
genes usw., welche man auch zu selbständigen Gruppen rechnet, die sich aber agglutinatorisch auch nicht einheitlich verhalten.

Für den praktischen Bakteriologen haben die Hofmannschen Bazillen bei weitem ein viel größeres Interesse als die Xerosebazillen, weil eben die diphtherische Konjunktivitis im Verhältnis zur Rachendiphtherie zu den Seltenheiten gehört, also die differentielle Diagnostik fast nie in Betracht kommt, während diese gerade bei der Rachendiphtheriefast täglich vorkommt.

Die Gruppe der Hofmannschen Bazillen wird also die im nächsten Absatz zu besprechende Pseudodiphtheriebazillenart sein.

Für ein gutes Verständnis ist ein kurzer historischer tberblick über beide Organismen, die Parasiten und Saprophyten, an diesem Orte nicht überflüssig.

\section{Historische Übersicht.}

In den Verhandlungen des Kongresses für innere Medizin (Wiesbaden 1883) lesen wir, daß Klebs an der Peripherie der diphtherischen Membranen, welche er mit Methylenblau färbte, kurze schlanke Stäbchén gefunden hatte, von unregelmäßiger Lagerung, mit "Sporen“ an jedem Pol des Bacillus. Er meinte, daß es eine zweite Form von Diphtherie gäbe, nicht, wie die erste, verursacht durch das Microsporon Diphthericum (womit er verschiedene Kokkenarten meinte), sondern durch dieses kurze, schlanke Stäbchen. Als er die diphtherische Membran über Schwefelsäure trocknete, entstanden in den Stäbchen mehrere,,Sporen “. Einzelne Stäbchen enthielten deren nicht weniger als 4. - Hier sehen wir also schon eine ganz primitive Polfärbung; infolge der Säurebehandlung wurde eben der Farbstoff von den Polkörnern viel intensiver aufgenommen als von dem Bazillenleibe, weshalb Klebs auch so viele sogenannte "Sporen" sah. Bei der damaligen bakteriologischen Technik war es Klebs unmöglich, diese Stäbchen rein zu züchten.

In der Diskussion, welche danach stattfand, sagte Edlefsen, daß er dieselben Stäbchen bei den Diphtheriefällen, welche er in Kiel beobachtet hatte, konstant angetroffen habe.

Im Jahre 1884 kommt Loeffler mit seiner ungemein wichtigen Mitteilung aus dem kaiserlichen Gesundheitsamte, in der er die Resultate seiner auf Anreging von Koch ausgefïhrten Diphtherieuntersuchungen bespricht und den Beweis liefert, daß die schon von Klebs beobachteten Stäbchen das ätiologische Moment der Bretonneauschen Diphtherie seien, weil diese Organismen ganz den drei Anforderungen genügen, welche nach Koch an einen Organismus gestellt werden müssen, will man ihn als das ätiologische Moment einer bestimmten Krankheit betrachten, nämlich: 
1. Dals aer rarasit in jedem einzelnen Falle der betreffenden Krankheit anzutreffen ist, und zwar unter Verhältnissen, welche den pathologisehen Veränderungen und dem klinisehen Verlauf der Krankheit entsprechen.

2. Daß er bei keiner anderen Krankheit als zufälliger und nicht pathogener Schmarotzer vorkommt.

3. Daß er von dem Körper vollkommen isoliert und in Reinkulturen hinreichend oft umgezüchtet imstande ist, von neuem die Krankheit zu erzeugen.

Diesem Organismus gab Loeffler den Namen Bacillus diphtheriae.

Die zweite Aufgabe, welche Loeffler sich stellte, war die Untersuchung von ganz Gesunden, um festzustellen ob-der Diphtheriebacillus auch bei ihnen vorkäme. Zu diesem Zweck untersuchte er Rachenschleim und Zahnfleisch von 10 gesunden Erwachsenen und 20 gesunden Kindern von 1 bis 8 Jahren alt. In 3 Fällen fand er große, mattweiße Kolonien auf der Platte, nach dem mikroskopischen Befund aus kurzen Stäbchen bestehend, welche nicht die typische Diphtherieform zeigten und für Meerschweinchen nicht pathogen waren. (Dies sind wohl schon Hofmannsche Bazillen gewesen.)

In einem Falle fand er aber typische Diphtheriebazillen, welche dem Meerschweinchen gegenüber sich als pathogen erwiesen. Dieser letzte Befund hat Loeffler zunächst zweifeln lassen, ob die keulenförmigen Stäbchen wirklich das ätiologische Noment der Diphtherie seien, oder ob sie doch als normale Rachenbewohner anzusehen wären. Dazu kamen noch zwei Tatsachen, welche auch nicht stimmten, 1. daß die Diphtheriebazillen nicht in allen diphtherischen Membranen angetroffen wurden; 2. daß die durch diese Organismen auf der Rachenschleimhaut tracheotomierter Kaninchen erzeugten Membranen nicht dieselbe Struktur zeigten, wie die bei der menschlichen Diphtherie gefundenen Pseudomembranen. Der Befund des virulenten Diphtheriebacillus beim völlig gesunden Kinde hat Loeffler aber sofort auf den Gedanken gebracht, daß diese Bazillen, in Anbetracht der zurzeit überall in Deutschland endemisch herrschenden Diphtherie, sehr gut in den Rachen dieses Kindes gekommen sein könnten, ohne daß sie dort pathologische Wirkung zu entfalten brauchten.

Am 21. April 1887 teilte Loeffler in der Berliner militärärztlichen Gesellschaft die Resultate seiner letzten Untersuchungen über Diphtherie mit, wobei er u. a. sagte, daß er immer mehr zu dem Urteil hinneigte, die keulenförmigen Stäbchen doch als das ätiologische Moment der Diphtherie anzusehen. - Weiter besprach er auch den wichtigen Befund, daß er bei einem Diphtheriekranken, einen Tag nachdem sich die typischen Symptome zeigten, neben dem Bac. diphtheriae ein diphtherieähnliches 
Stäbchen fand, das aber kürzer und kleiner war und für das Meerschweinchen keine Pathogenität zeigte.

Bei einem letal geendeten Diphtheriefall, bei dem die Obduktion von Prof. Heller in Kiel ausgefuihrt war, wurden auch im Magen diphtherische Membranen gefunden. Eine Kultur, welche davon hergestellt wurde, ergab neben dem typischen virulenten Diphtheriebacillus auch ein ähnliches Stäbchen, das aber völlig avirulent, kleiner war als der virulente Diphtheriebazillus und die kolbigen Endanschwellungen weniger reichlich zeigte. Darauf legt Loeffler ganz speziell den Nachdruck, daß es eben auch avirulente Organismen gäbe, welche morphologisch den Diphtheriebazillen sehr ähnlich sind. Er hält es für unbedingt notwendig, bei jeder bakteriologischen Untersuchung dieser Krankheit die gezüchteten Bazillen auf ihr Verhalten dem Meerschweinchen gegenüber $z u$ prüfen, damit man diese zwei verschiedenen, sehr ähnlichen Bazillenarten voneinander zu trennen imstande wäre. Er glaubt entschieden, daß es bei scharfer Beobachtung der morphologischen und biologischen Kennzeichen möglich wäre, diese Pseudodiphtheriebazillen stets von den echten $\mathrm{zu}$ unterscheiden.

Hier sehen wir also schon zur Zeit, wo das eigentliche Diphtheriestäbchen erst entdeckt wurde als das ursächliche Agens der Diphtherie, auch alle die Schwierigkeiten zutage treten, womit die späteren Bakteriologen zu kämpfen hatten und eigentlich noch zu kämpfen haben, nämlich:

1. Daß nicht in allen diphtherischen Membranen die Diphtheriestäbchen angetroffen wurden.

2. Das Vorkommen von Pseudodiphtheriebazillen neben den echten Diphtheriebazillen.

3. Das Vorkommen der echten Diphtheriebazillen nicht nur bei Diphtheriekranken, sondern auch bei völlig Gesunden, welche mit Diphtheriekranken in Berührung gekommen sind.

Im selben Jahre (1887) erscheint die Publikation von v. HofmannWellenhof, in der er speziell die Frage der Pseudodiphtheriebazillen bespricht. Er fand diese Organismen bei Diphtherie, Morbilli, Scarlatina, Katarrh des Pharynx und auch auf ganz normalen Rachen- und Nasenschleimhäuten. Bei 45 gesunden Personen fand er 26 mal Pseudodiphtheriebazillen, also bei 57.5 Prozent. Bei 7 Fällen von typischer Diphtherie wurden von ihm sehr virulente, avirulente, auch mehr oder weniger virulente Diphtheriebazillen gefunden.

Hofmann hat damit den Beweis liefern können, was Roux später auch hat zugeben müssen, daß die Virulenz des Bac. diphtheriae keine konstante Größe ist, wodurch ein wichtiges differentielles Diagnosticum zwischen beiden Organismen fortfiel. 
Weil v. Hofmann die sogenannten Pseudodiphtheriebazillen genau studiert und beschrieben hat, gibt man ihnen auch wohl den Namen Bac. Hofmanni.

Aus dem Vorhergesagten ist wohl deutlich zu ersehen, daß die Trennung dieser zwei verschiedenen Organismen nicht so einfach und leicht ist, wie Loeffler sich das ursprünglich dachte.

Nach dieser Publikation hat der große Kampf (welcher heutzutage noch besteht) in seinem ganzen Umfange begonnen.

Auf der einen Seite die französische Schule mit Roux, Yersin, Martin, Schanz, Fraenkel, Abbott, von Behring, Lesieur, Lambotte, Roussel und Malard usw. als ,Unizisten“, welche den Pseudodiphtheriebacillus als ein avirulent-atoxisch gewordenes Diphtheriestäbchen ansehen, ihnen gegenüber Loeffler, v. Hofmann-Wellenhof, Zarnico, Escherich, Beck, Fraenkel, Spronek, Graham Smith, Neisser u. a..als ,Dualisten“, welche die Pseudodiphtheriebazillen als selbständige Organismen betrachten. Ein interessantes Beispiel für die Schwierigkeit dieses Problems habe ich immer in Fraenkel gefunden, der bis 1893 völlig Unizist war, im Jahre 1896, also drei Jahre später, Vollblut-Dualist wurde.

Man kann freilich sagen, daß es kaum eine kulturelle, biologische oder tinktorielle Methode gibt, welche nicht zur Differenzierung dieser beiden Organismen herangezogen worden ist.

Die vornehmsten sind: Morphologie - Polfärbung auf alle verschiedene Weisen - Säurebildung aus verschiedenen Zuckerarten - Virulenzprüfung - Agglutination - Präzipitation - Bakteriolyse - Komplementablenkung usw. Die Resultate sind, wenn man in der fabelhaften Menge von Literatur herumschaut, leider so inkonstant und so widersprechend, die unizistischen und dualistischen Anschauungen noch so häufig, daß man sich kaum ein richtiges Urteil über die Frage bilden kann. - Eigene Erfahrung, Selbstausprobieren, selbst den Wert dieser verschiedenen Reaktionen nachprüfen, eingehende, kritische Erforschung der biologischen und epidemiologischen Verhältnisse, ist der einzige Weg welcher zu einem Ziele führt, und welcher es ermöglicht, daß man über eine so äußerst praktische Frage zur Klarheit kommt.

Die rein bakteriologischen Untersuchungen, welche ich über dieses Problem anstellte, wurden von mir ausführlich im Zentralblatt für Bakteriologie veröffentlicht. Auf diesem Wege bin ich schon zur völligen Überzeugung gekommen, daß der Bac. diphtheriae und der Bac. Hofmanni ganz entschieden zu zwei verschiedenen Bazillenarten gerechnet werden 
müssen. Die Untersuchungen am kranken Kinde und einer großen Anzahl von gesunden Kindern (Diphtkeriekontakte) von mir angestellt, haben mir genügenden Anla $B$ gegeben, diese wichtige Frage von ganz anderem Standpunkt aus anzusehen.

Es geniigt nicht, nur im Laboratorium mit Kulturen zu arbeiten, welche aus ihrem natürlichen Milieu herausgenommen sind, welche auf den verschiedensten künstlichen Nährmedien fortgezïchtet und weiter den eingreifendsten Methoden unterworfen werden, mit anderen Worten, die Organismen nur in unnatürlichem Verhältnisse kennen zu lernen; die Erforschung des fraglichen Organismus an seinem natürlichen Standorte, also die biologisch-epidemiologische Forschung, kann uns vielleicht besser zum Ziele führen und eine verläßliche Bestätigung der Resultate geben, welche nur am Laboratoriumstisch erzielt wurden.

$\mathrm{Zu}$ diesem $\mathrm{Zweck}$ habe ich versucht, diese Frage vom rein biologisehepidemiologischen Standpunkte aus zu studieren und auf folgende zwei Fragen eine Antwort zu geben:

1. Wo und bei wem werden Bac. diphtheriae und Bac. Hofmanni am häufigsten gefunden?

2. Müssen Bac. diphtheriae und Bac. Hofmanni aus biologischepidemiologisehen Gründen zu zwei verschiedenen Bazillengruppen gerechnet werden?

Zuerst werde ich die Gruppe der typischen Diphtheriebazillen behandeln.

\section{Zur Lokalisation des Bac. diphtheriae im mensehlichen Körper.}

Jeder Mikroorganismus, ob er zu den Prototrophen, Metratrophen oder Paratrophen gehört, hat nach seinen chemisch-physisch-physiologischen Leistungen in der Natur seinen bestimmten Standort bekommen, wo er am vorzüglichsten die für seine Art typische Form und Eigenschaften entfalten und behalten kann. Die Mikroorganismen (Saprophyten- und Halbparasiten), welche sich im gesunden menschlichen Körper aufhalten, und die Halbparasiten (fakultative) und obligaten Parasiten, welche im menschlichen Körper an Sehleimhäuten und Organen gewisse Krankheiten hervorrufen können, haben auch da für ihre Art besonders bevorzugte Plätze. Wenn wir uns auf die medizinische Bakteriologie beschränken, so vergegenwärtigen wir uns bei einem jeden Organismus Herkunft, Ort und Stelle wo er am häufigsten angetroffen wird, die Schleimhaut(häute), zu denen er die größte Affinität besitzt. So findet man z. B. Bact. coli meistens im Kolon; Bact. paratyphi B im Darm; Bact. typhi im Anfang der Krankheit im Ileum und im Blute, später in den Fäces und in der 
Galle; Vibrio cholerae im Darm; Pneumococcus im Tractus respiratorius; Gonococcus im Urogenitalapparat; Meningococcus im Retropharyngealschleim und den Meningen; Bact. pestis im Lofmphapparat, Lungen, Blut usw. und Bac. diphtheriae auf der Rachenschleimhaut.

In pathologischen Zuständen werden in dieser Beziehung beim Fortschreiten der Krankheit wohl kleinere und größere Störungen hervorgebracht, wodurch andere Schleimhäute mit erkranken und Auswanderungen ins Blut stattfinden können. Ferner kommt die allgemeine Herabsetzung der natürlichen körperlichen Wehrmittel in Betracht, wodurch Misch- und Sekundärinfektionen auftreten können, wo Saprophyten plötzlich eine erhöhte Virulenz zeigen, oder andere Parasiten, welche sonst harmlos wären, zur Sepsis führen können.

In diesen Fällen spielen dann so viele hinzukommende Faktoren eine Rolle, daß kaum noch von den mehr natürlichen Verhältnissen die Rede sein kann. In der Regel aber entfalten die pathogenen Organismen ihre krankmachenden Eigenschaften zuerst auf den Geweben, zu denen sie die gröbte Affinität besitzen.

So ist es eben mit dem Diphtheriebacillus auch; der krankhafte Prozeß fängt fast immer auf der Rachenschleimhaut an, zu der der Diphtheriebacillus die größte Affinität hat. Schreitet die Entziindung weiter, so beobachtet man meistens zuerst eine Ausbreitung nach den unteren Luftwegen, Pharynx, Larynx, Trachea, Bronchi. Geht es noch weiter, dann werden Nasenhöhle, Nasennebenhöhlen, Mittelohr usw. angegriffen. Bei letal endigenden Fällen hat man dann und wann auch Diphtheriebazillen im Blute, in der Leber und Milz angetroffen; dies gehört aber zu den Seltenheiten und wird wohl nur da stattfinden können, wo der Prozeß ein so bösartiger ist, und die natïrlichen Wehrmittel dermaßen herabgesunken sind, daß es zu einer Septikämie kommen kann. Die schönen Untersuchungen Becks haben im Tierexperiment erwiesen, daß der Diphtheriebacillus nicht in den Körper und ins Blut auswanderte, nicht auf gesunden Schleimhäuten zu leben imstande ist, sondern sich nur da ansiedelt und wächst, wo die Mukosa durch Epitheldefekte ihm gute Wachstumsbedingungen bietet. Mallory stellt es sich so vor, daß die eigentlicheEntzündung anfängt durch das Toxin der Diphtheriebazillen, welche sich im Rachen oder Speichel befinden. - An diesen Stellen nekrotisiert die Schleimhaut, eine Membran formt sich auf der Oberfläche, und da siedeln sich jetzt die Diphtheriebazillen an und können erst in diesem sehr eiweißreichen Milieu sich vermehren und viel Toxin produzieren.

Die Menge Untersuchungen, welche angestellt worden sind, um beim an Diphtherie erkrankten Menschen und bei infizierten Tieren im Blute 
und den Organen Diphtheriebazillen nachzuweisen, sind denn auch meistens erfolglos gewesen; beim infizierten Tier kann man sie höchstens noch an der Injektionsstelle wiederfinden, wo sie aber auch bald absterben. Bonhoff, der sehr zuverlässige Untersuchungen anstellte und das Leichenblut von 314 Diphtheriekranken bakteriologisch untersuchte, fand bei zehn Fällen Diphtheriebazillen und Streptococcus pyogenes im Blute, also eine Mischinfektion; nur bei drei Fällen, also 0.95 Prozent, allein Diphtheriebazillen. Wenn man bedenkt, daß es sich hier um die schwersten Diphtherieformen handelt, so ist dieser Befund auffallend wenig.

Was die diphtherischen Erkrankungen an anderen Stellen des menschlichen Körpers anbelangt, z. B. Hautdiphtherie, Wunddiphtherie, diphtherische Abszesse, Vulvadiphtherie, Diphtherie der Genitalien usw., so sind diese selten. Die Wunddiphtherie tritt öfters anf an der Tracheotomiewunde. - Fast immer hat man sie zurückführen können auf Sekundärinfektionen vom Rachen aus. Man hat sich das so vorzustellen, daß Diphtherie des Rachens bestand, oder Diphtheriebazillen auf der gesunden Rachenschleimhaut zu finden waren, und durch kratzende Finger die Diphtheriebazillen weiter über den Körper verbreitet wurden, daß also diese Infektionen als sekundäre $z u$ betrachten sind.

Der Fall Schottmüllers gibt davon ein schönes Beispiel: Bei einem kleinen Kinde zeigte sich in der Leiste eine Wunde mit deutlichen Pseudomembranen. Diphtheriebazillen konnten herausgezüchtet werden. Obwohl der Rachen normal war, konnten die Diphtheriebazillen in Reinkultur von dieser Schleimhaut isoliert werden. Das Kind hatte ein Püstelchen in der Leistengegend gehabt und es mit dem Finger, an dem Diphtheriebazillen aus dem Rachen hafteten, aufgekratzt und so selbst die schwere diphtherische Entzündung in der Leiste hervorgerufen. Der Bruder dieses Kindes war zwei Wochen zuvor an Diphtherie gestorben; die Herkunft der Diphtheriebazillen war also klar.

Einen anderen Fall erzählt Bauer: Bei einem Fall von Rachendiphtherie, wo sich an den Mundecken diphtherische Abszesse zeigten, trat ein diphtherisches Panaritium auf, in dessen Eiter typische Diphtheriebazillen nachgewiesen werden konnten. Das Kind hatte nämlich die Gewohnheit, mit dem Finger an der Unterlippe zu saugen. - Diese Fälle könnte man noch mit vielen ähnlichen ergänzen. [Hàla, Jèz, Williams, Seitz, Salmon, Mc Collom (siehe Graham Smith); Jochmann usw.]

Der Diphtheriebacillus hat also eine ausgesprochene Affinität zur Rachenschleimhaut und wird, wie wir weiter sehen werden, am häufigsten nicht auf der normalen, sondern anf der an Diphtherie erkrankten Rachenschleimhaut gefunden. 


\section{Der Klebs-Loefflersehe Diphtheriebaeillus in dem aur Diphtherie erkrankten Pharynx.}

Durch die Entdeckung Loefflers im Jahre 1884 ist das KlebsLoefflersche keulenförmig angeschwollene, grampositive Stäbchen als das ätiologische Moment einer Rachenkrankheit erkannt, welche schon seit dem ersten Jahrhundert bekannt war, und der man seitdem die verschiedensten Namen gegeben hat. Je nachdem die Krankheit lokalisiert war auf den Tonsillen (Ulcera pestifera), im Pharynx (Morbus strangulatorius), im Larynx (Morbus suffocatus; Asthma acutum) wurde der Krankheit ein anderer Name gegeben, und wurden sie jede für sich als ganz selbständige Krankheiten aufgefaßt, welche in keiner Hinsicht miteinander übereinstimmten. - Dem genialen Bretonneau verdanken wir es, daß er in diesem Chaos einige Ordnung geschaffen hat. Durch die furchtbaren Angina-Epidemien in Tours, Ferrière und Chenuson (1818 bis 1826) war Bretonneau, der damals Arzt im Krankenhaus zu Tours war, in den Stand gesetzt, diese Krankheit in ihrem ganzen Umfange, sowohl klinisch wie pathologisch-anatomisch zu studieren. Er konnte feststellen, daß alle diese verschiedenen Pharynx- und Larynxkrankheiten durch dieselbe Struktur, welche die Pseudomembranen zeigten, eine und dieselbe Krankheit darstellten und die gleiche Aetiologiam morbi hatten. Bretonneau gab dieser Krankheit den Namen $\delta\llcorner q \vartheta \dot{\varepsilon} \rho \alpha$; was „Membran“" (Haut) bezeichnet.

Die Angina diphtherica möchte ich in zwei Gruppen unterbringen:

A. Angina diphtherica: wo der für Diphtherie typische Symptomenkomplex klinisch so deutlich vorhanden ist, daf man imstande ist, die Diagnose Diphtherie ohne weitere bakteriologische Hilfe zu stellen.

B. Angina diphtherica: wo der klinische Symptomenkomplex demjenigen einer Angina tonsillaris, katarrhalisehen Angina oder ganz leichten Angina entspricht, weshalb die diphtherische Ätiologie nur durch den Bakteriologen festgestellt werden kann (rudimentäre Diphtherie).

Selbstverständlich ist, daß man zwischen diesen beiden Anginaextremen noch viele sogenannte „Ubergangsformen" hat, welche eben vom Arzt als „verdächtige" Angina diagnostiziert werden.

A. In wieviel Fällen von klinisch diagnostizierter Rachendiphtherie konnten die Klebs-Loefflerschen Bazillen nachgewiesen werden?

In der interessanten Diphtherie-Monographie von Graham Smith fand ich folgende Zahlen aufgezeichnet: 
Von 2846 Diphteriefällen, von 1886 bis 1896 in Europa bakteriologisch untersucht, wurden Diphtheriebazillen gefunden bei Im Institut Pasteur von 960 untersuchten Diphtheriefällen Bac. diphtheriae bei .............. . .

In Deutschland während 1894 von 972 untersuchten Diphtheriefällen Bac. diphtheriae bei . . . . . . . . . .

Park und Morse von 5340 untersuchten Diphtheriefällen Bac. diphtheriae bei . . . . . . . . . . .

Josias und Tollemer von 709 untersuchten Diphtheriefällen Bac. diphtheriae bei . . . . . . . . . . .

Weiter noch von mir selbst gesammelte Prozentzahlen: Martin von 193 untersuchten Diphtheriefällen Bac. diphtheriae bei .

Roux und Yersin von 80 untersuchten Diphtheriefällen Bac. diphtheriae bei ......................... Muysken in Holland von 116 untersuchten Diphtheriefällen Bac. diphtheriae bei . . . . . . . . . . Heubner von 193 untersuchten Diphtheriefällen Bac. diphtheriae bei . . . . . . . . . . . . . . Im Hygienischen Institut in Bremen während 1904 bis 1905 von 1404 untersuchten Diphtheriefällen Bac. diphtheriae bei Baginsky von 154 untersuchten Diphtheriefällen Bac. diphtheriae bei .

Morel von 86 untersuchten Diphtheriefällen Bac. diphtheriae bei . . . . . . . . . . . 76.7 ", Durchschnittlich erhalten wir hier als Prozentzahl . . . 80.0 ",

Man hätte vielleicht eine höhere Durchschnittsprozentzahl erwartet; auch sind die Zahlen im einzelnen ziemlich großen Schwankungen unterworfen ( 67.0 bis 99.0 Prozent), aber dies muß uns nicht wundern. Es ist an dieser Stelle wohl nicht überlliussig, einen Augenblick die Aufmerksamkeit auf die Faktoren zu lenken, welche den bakteriologischen Befund direkt und indirekt sehr beeinflussen können. Bei jedem Diphtheriepatienten, welcher zur bakteriologischen Untersuchung kommt, spielen nämlich 3 Faktoren eine wichtige Rolle:

1. Der Kliniker.

2. Die Weise, in der die Entnahme des Schleims stattfindet.

3. Der Bakteriologe.

1: Was die klinische Diagnose betrifft, so wissen wir alle, daß die sogenannten „Pseudomembranen“, eins der wichtigsten Symptome bei der 
Diphtherie, nicht nur von den Diphtheriebazillen, sondern auch von anderen Mikroorganismen verursacht werden können.

Die Streptokokkenanginae, welche so oft bei Scarlatina beobachtet werden,

die Staphylokokkenanginae,

die Pneumokokkenanginae,

die Plaut-Vincentschen Anginae, vom Bac. fusiformis verursacht, können eine diphtherische Angina so vortäuschen, daß die differentielle Diagnose klinisch nicht zu stellen ist.

Diese klinisch der typischen Diphtherie sehr ähnlichen Anginen, bei denen man trotz mehreren sorgfältigen bakteriologischen Untersuchungen keine Diphtheriebazillen hat nachweisen können, verlaufen meistens ohne spezifische Behandlung mild und ohne Komplikationen, was auch für ihre Nicht-Diphtherienatur spricht.

Ich brauche nicht. weiter zu erörtern, wie gefährlich es eben für derartige Fälle ist, wenn sie in Krankenhäusern in die Diphtherieabteilung aufgenommen werden, weil sie eben als echte Diphtherie angesehen werden. Die Infektion mit Bac. diphtheriae wird dann auf der schon kranken Schleimhaut eine noch viel schwerere und gefährlichere sein.

2. Bei der Entnahme des Rachenschleimes mittels des sterilen Wattetupfers, wie sie meistens durch den behandelnden Arzt áusgeführt wird, können auch einige Faktoren einen direkten Einfluß auf den späteren bakteriologischen Befund ausüben:

a) Das Gurgeln vom Patienten mit Antiseptica, was immer sofort vom Arzt befohlen wird. Die Zeit zwischen der letzten Mundspülung und der Schleimentnahme hat großen Einfluß auf die Vitalität des Diphtheriebacillus, was die praktischen Ärzte gar nicht immer bedenken.

b) Die Entnahme mittels des Tupfers selbst, die bisweilen von den Kindern kaum zugelassen wird. Weil die Diphtheriebazillen nicht gleichmäßig über die Schleimhaut verbreitet sind, sondern sich, wie ich schon frühier hervorhob, nur da ansiedeln, wo die Membranen sich befinden, sowie auf den Tonsillen, wo sie nesterartig angeordnet sind, kann eine Abwehrbewegung des Kindes leicht machen, daß eine Stelle abgestrichen wird, wo die Diphthericbazillen sich gar nicht oder sehr spärlich befinden. Dies gilt auch für den Diphtherierekonvaleszenten und gesunden Bazillenträger. Ich selber habe bei letzteren erfahren, wie schwer und mühsam es oft ist, bei kleinen Kindern von verschiedenen Rachenstellen Schleim zu entnehmen; schon das Öffnen des Mundes macht ihnen Angst. 
c) Das unmittelbar vorher stattgehabte Aushusten von Membranen und viel Exsudat, wodurch auch massenhaft Diphtheriebazillen mit entleert werden können.

d) Bei der gangränösen Diphtherieform das Mitschleppen von vielen Fäulnisorganismen, durch welche die Diphtheriebazillen später überwuchert werden.

e) Das mehr oder weniger schnelle Austrocknen des Materials am Wattetupfer, bevor dieser zur Untersuchung kommt, was auch sehr von der Beschaffenheit des Schleimes abhängig ist, was aber von den Diphtheriebazillen so schlecht vertragen wird.

3. Endlich die bakteriologische Untersuchung selbst, welche nicht immer mit derselben Genauigkeit und Zuverlässigkeit geschieht (schlechte Nährmedien, zu kurze Bebriitung, Untersuchung von zu wenigen Kolonien, in einem Worte schlechte Technik).

Aus all dem Vorhergesagten ist wohl deutlich zutage getreten, daß es viel unvermeidliche und vermeidliche Fehlerquellen gibt, welche einen großen direkten Einfluß ausüben können auf den späteren bakteriologischen Befund bei Diphtheriekranken.

Glïcklicherweise sind die unvermeidlichen Fehler hier an Zahl die geringeren.

B. Bei den diphtherischen Anginae, welche klinisch als gewöhnliche Anginae diagnostiziert wurden, zeigten sich doch viele als diphtherisch:

Der Massachusetts State Board of Health untersuchte 2340 Fälle von gewöhnlichen Anginae und konnte feststellen, daß Bac. diphtheriae gefunden wurde bei . . . 18 Proz. Glüeksmann in Zürich von 119 Anginaefällen Bac. diphtheriae bei . . . . . . . . . . . . . . $12 "$ Büsing in Bremen von 830 Anginaefällen Bac. diphtheriae bei 16 , Scheller von den Anginaefällen ,ohne irgendwelchen Belag"

Bac. Diphtheriae bei . . . . . . . . . . . . . 11 , Durchschnittlich also hier . . . . . . . . . . 14,

Diese atypischen Diphtherien sind viel häufiger als die nichtdiphtherischen Anginae, welche klinisch ganz dem Diphtherie-Symptomenkomplex entsprechen. Diese leichten atypischen Formen werden entweder von Diphtheriebazillen mit geringer Virulenz verursacht oder bei hoher Virulenz des Bacillus am hä̈ufigsten bei weniger Empfindlichen, zum Beispiel bei älteren Kindern und Erwachsenen vorkommen, da diese bekanntlich eine so viel geringere diphtherische Empfindlichkeit zeigen. 
Werden bei gewöhnlichen Anginae typische Diphtheriebazillen gefunden, so müssen sie als diphtherisch angesehen werden. Sind auch die klinischen Symptome sehr mild, so hat man solche Patienten dennoch epidemiologisch als eine große Infektionsgefahr zu betrachten und gerade bei der Bekämpfung einer Epidemie sehr auf diese rudimentären Diphtherieformen zu achten.

\section{Die Klebs-Loefflerschen Diphtheriebazillen in der kranken Nase.}

Später, bei der Besprechung des Bac. Hofmanni, wird es deutlich werden, warum ich absichtlich die Nasenschleimhaut, welche so nah an der Rachenschleimhaut liegt, gesondert und so ausführlich behandele.

Die Nasenschleimhaut ist ein Luftfilter im vorzüglichsten Grade und macht, daß die Atmungsluft, welche täglich Millionen und Millionen pathogener und nichtpathogener Mikroorganismen in die Nase führt, fast keimfrei in die Trachea und die Lungen gelangt. Die Luftflora wird teils mechanisch im Vestibulum nasi durch die Vibrissae, Flimmerepithel, Nasenabfluß zurückgehalten und fortgeführt, teils sind es die stark bakteriziden Eigenschaften des Nasenschleims und der Schleimhaut, welche die Organismen in ihrer Entwicklung hemmen und abtöten. Dieser Beschaffenheit des Nasenschleims ist es eben zu verdanken, daß die Nase so selten primär erkrankt.

Die Diphtherie ist von jeher bekannt als eine primäre Rachenkrankheit. Interessant ist es jedoch zu untersuchen, wie sich der Diphtheriebacillus eben zur Nasenschleimhaut verhält. Erst seit die Bakteriologie an der diphtherischen Diagnostik ihren Anteil bekommen hat, sind die diphtherischen Nasenerkrankungen bekannt geworden.

Die sogenannten Nasendiphtherien lassen sich in 3 Gruppen unterbringen:

1. Die primäre Nasendiphtherie (Rhinitis crouposa oder Rhinitis diphtherica) ist eine echte diphtherische Entzündung mit eitrigem, auch wohl blutigem Ausfluß aus der Nase und Pseudomembranen, wodurch Stenose der Nasengänge eintritt, Fieber und allgemeines Kranksein des Patienten. Im Nasenschleim sind typische Diphtheriebazillen nachzuweisen. Öfters tritt auch Krustenbildung an den Nasenflügeln auf. Diese eingreifende Entzündung bleibt nicht immer in der Nase lokalisiert, sondern greift gern auch auf Rachen und Larynx über. - Serumtherapie ist hier auch besonders angezeigt und gibt die schönsten Erfolge.

2. Die sekundäre Nasendiphtherie, ganz dieselbe Krankheit wie 
die eben beschriebene, nur daß sie sekundär bei Rachendiphtherie auftritt und als eine Ausbreitung der Rachenentzündung aufgefaßt werden muß.

3. Die Rhinitis fibrinosa oder Rhinitis pseudomembranacea, welche erst 1866 von Demme beschrieben worden ist. Diese Entzündung fängt wie ein heftiger Schnupfen an, mit starkem Ausflub; nach einigen Tagen tritt Stenose der Nasengänge durch fibrinöse Pseudomembranen, auf, welche fest auf der stark geschwollenen und hyperämischen Schleimhaut haften und entweder von den Patienten selber ausgestoßen werden oder mittels einer Pinzette abgenommen werden können, wonach eine geringe Blutung auftritt, und die Membranbildung aufs neue anfängt. Nach 8 bis 14 Tagen werden die Membranen vom Patienten selber spontan abgestoßen und ausgeniest, wonach völlige Heilung stattfindet. Die Krankheit bleibt in dex Nase lokalisiert, es besteht kein Fieber, und das Wohlbefinden des Patienten ist gar nicht gestört.

1. Das Vorkommen der primären Nasendiph therie. - Wenn man nur die Literaturangaben beriicksichtigt, in denen neben der genauen bakteriologischen Untersuchung auch der klinische Symptomenkomplex in allen Einzelheiten aufgezeichnet ist, erscheint es wirklich auffallend, wie selten eben die primäre Nasendiphtherie vorkommt.

Von den zahllosen Untersuchern abgesehen, welche kein einziges Mal von einer primären Nasendiph therie reden-Roux und Yersin (14 Fälle), Martin (200 Fälle), Muysken (133 Fälle), Beck (83 Fälle), Kossel (14 Fälle), Slawyk und Manicatide (28 Fälle), Baginsky (525 Fälle), Max Cohn (1000 Fälle) (der letzte hat von 1000 Diphtheriekranken etwa 50 schon am ersten Krankheitstage ins Krankenhaus bekommen) - finden wir folgendes:

Welch hatte unter 6156 klinisch verdächtigen Diphtheriefällen in New York, welche er bakteriologisch untersuchte, nur 4 Fälle primärer Nasendiphtherie, also nur . . . 0.065 Proz. Glücksmann in Zürich von 520 klinischen Diphtherien nur . 4 Fälle von Rhinitis diphtherica $=$. . . . . . . . . Scheller von 897 von ihm bakteriologisch festgestellten Diphtheriefällen Rhinitis diphtherica in nur ... . 2. 2.0 ", 91.3 Prozent waren Rachendiphtherie.

Hasslauer fand unter 47 kranken Nasen, welche er untersuchte, keinen einzigen Fall von diphtherischer Rhinitis. Wolff sah unter 23 sehr schweren Rachendiphtherien, wo keine Serumtherapie angewandt wurde, und welche alle letal endigten, nur zwei, bei denen der Krankheitsprozeß auf der Nasenschleimhaut angefangen hatte, also . . 8.0 " 
Im großen Sammelreferat von Hasslauer über ,Die Mikroorganismen der gesunden und kranken Nase" sind nur einige Fälle von primärer Rhinitis diphtherica beschrieben; sie sind auch da als eine ziemlich seltene Krankheit bezeichnet.

Obwohl es schwer ist, aus diesen Zahlen eine Durchschnittsprozentzahl zu berechnen, kann man doch sagen, daß die primäre Nasendiphtherie kaum $1 / 2$ Prozent der Diphtheriefälle beträgt.

2. Das Vorkommen der sekundären Nasendiphtherie. - Das sekundäre Erkranken der Nase bei Rachendiphtherie ist häufiger, als das primäre.

So fand Muysken unter 133 typischen Dyphtheriefällen bei

5 , wovon 1 letal endigte, eine ausgesprochene sekundäre

Nasendiphtherie, also bei .......... 3. . . Proz.

49.0 Prozent zeigten eine vorübergehende erhöhte. Sekretion der Nase. Es. ist natürlich schwer zu sagen, weil Muysken die Nase nicht bakteriologisch untersuchte, ob diese erhöhte Sekretion Diphtheriebazillen, welche vom Rachen aus in die Nase gelangt waren, zuzuschreiben ist, oder $o b$ sie als eine regionäre Schleimhautreizung aufgefaßt werden muß, weil Nasen- und Rachenhöhle bei Kindern so nah aneinander liegen.

Baginsky sah bei seinen 525 ausgesprochenen Diphtheriefällen bei $109=21$ Proz. Nasensymptome (Rhinitis Katarrh - erhöhte schleimige - seröse oder eitrige Sekretion). - Bei 56 Fällen aber eine ausgesprochene sekundäre Nasendiphtherie mit Membranen also bei 10.6 Proz. Beck sah unter 53 klinisch und bakteriologisch sicher festgestellten Diphtheriefällen bei 4 sekundäre Nasensymptome (3 davon starben)

Kossel unter 14 von ihm balrteriologisch untersuchten Diphtheriefällen 2 sekundäre Nasensymptome ....... $\pm 14 \cdot 0$,

Roux und Yersin: Unter 14 Fällen, welche sehr genau klinisch und bakteriologisch beschrieben werden, wird nur von einem Fall gesagt "les liquides ressortent du nez"; = 7.0 , Jener Fall war eine sehr heftige Rachendiphtherie.

Martin sah unter 200 Fällen, wo keine Serumtherapie angewendet werden konnte, wo also nichts Spezifisches die Krankheit beeinflußt hatte, sekundäre Nasensymptome bei . . 0.0 ,

Slawyk und Manicatide unter 28 Diphtheriefällen bei 2 Fällen Nasensymptome . . . . . . . . $7 \cdot 0$, 
Max Cohn: Unter 1000 Fällen von klinisch und bakteriologisch bestätigter Diphtherie waren bei 167 Fällen Rachen und Nasen erkrankt . . . . . . . . . 16.7 Proz.

Wolff: Unter 23 sehr schweren und ausnahmslos letal endigenden Fällen sekundäre Nasensymptome bei . . . . 38.0 ",

Diese Beobachtungen gehen ziemlich weit auseinander, aber es ist aus ihnen deutlich zu ersehen, daß die sekundären Nasendiphtherien häufiger sind als die primären. Bei Wolff, welcher die höchste Zahl von beiden beobachtete, tritt dieser Unterschied auch deutlich hervor.

Man könnte noch behaupten, weil die Nasendiphtherien meistens so leicht verlaufen, daß die Aufmerksamkeit des Klinikers an erster Stelle auf die viel schwereren Rachensymptome gelenkt ist, und deswegen die Nasensymptome übersehen werden. Diese Bemerkung ist mir in der Tat gemacht worden.

Würde dies wirklich so sein, dann können nur die Pathologanatomen, welche gerade die schwersten Diphtheriefälle beobachten, die Antwort hierauf geben. Ist der Krankheitsprozeb zur Nasenhöhle fortgeschritten, so wird die Sektion es feststellen können:

Wolff, der ganz ausführliche und zuverlässige Untersuchungen über die ,Nebenhöhlen der Nase bei Diphtherie, Masern und Scharlach" anstellte, fand unter 23 letal endigenden schweren Diphtherien, welche von ihm seziert wurden, bei 12 deutliche Pseudomembranen in der Nasenhöhle, also bei ............. 50.0 Proz.

Er sagt: „Die Diphtherie der Nasenhöhlen hat jedesmal auf die Nebenhöhlen übergegriffen. Kommt es zu einer pseudomembranösen Nasendiphtherie, so wandert der Diphtheriebacillus in die Nebenhöhlen (Highmorshöhle, Stirnhöhle, Paukenhöhle, Keilbeinhöhle) hinüber. In den Nebenhöhlen bleiben dann die Diphtheriebazillen zurück. Bei Nasendiphtherie wird nach der Komplikation mit Sepsis die schlechteste Prognose gestellt."

Mallory, der 251 Diphtheriefälle im ,Contagious Department of the Boston City Hospital" sezierte, konnte Pseudomembranen nachweisen, welche auf folgende Weise Iokalisiert waren:

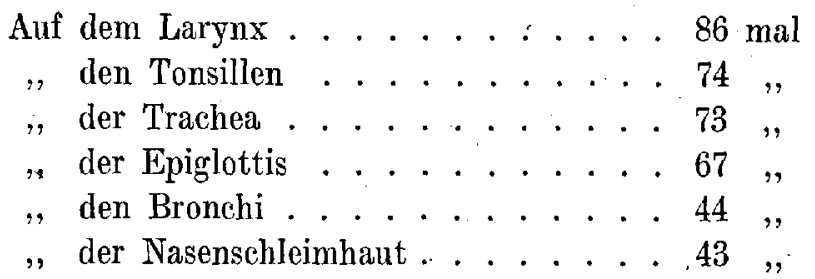




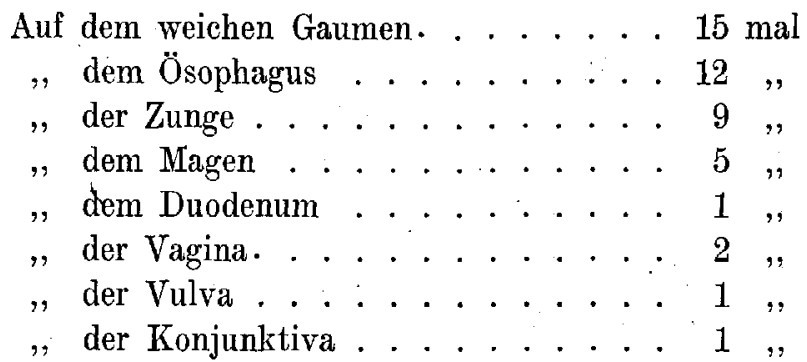

Bei 315 Fällen ist also die Rachenhöhle ergriffen und nur bei 43 die Nasenschleimhaut.

Max Cohn gibt von seinen 1000 Fällen eine Mortalitätsstatistik, und es ist auffallend, daß mit der Ausbreitung der Rachendiphtherie die Mortalität eine höhere wird:

Lokalisation der Krankheit

338 mal auf Tonsillen (Erwachsener)

151 , , Tonsillen und Rachen .

167 ,, , Rachen und Nasen . .

172 " , Larynx ... . . .

172 , ein deszendierenter Prozeß
Todesfille

64

Er sagt: „In den ausgesprochenen Sepsisfällen stellten die Nasenrachendiphtherien das Hauptkontingent."

Baginsky konnte bei seinen 525 ausgesprochenen Diphtheriefällen folgende Lokalisation der Pseudomembranen feststellen:

\begin{tabular}{|c|c|c|}
\hline Auf Tonsillen & $316 \mathrm{mal}$ (Kinder) & $\begin{array}{l}\text { Todesfälle } \\
6 \cdot 3 \text { Proz. }\end{array}$ \\
\hline „, Tonsillen und Rachen & $209,,(,)$, & $21 \cdot 5 \quad$, \\
\hline Nasen und Rachen. & $56, n(,)$, & $38 \cdot 0$ \\
\hline
\end{tabular}

Wir sehen also, daß die pathologisch-anatomischen Ergebnisse die klinischen ergänzen, und daß die Nasendiphtherie, wenn sie auftritt, - meistens als eine Ausbreitung des Rachenprozesses anzusehen ist, welche sofort die Prognose sehr ungünstig macht.

Die ganz leichten, atypischen Nasendiphtherien.

Ebensogut, wie es' sehr milde, atypische Rachendiphtherien gibt, bei denen die klinischen Symptome so leicht sind, daß man sie fast nicht bemerkt, gibt es auch Nasendiphtherien, welche unter dem Bilde einer Coryza oder leichten Rhinitis verlaufen, dann und wann mit einer gewissen Hyperämie des Rachens. Der Patient fühlt sich unwohl, sieht anämisch aus, hat etwas frequenten Puls, ohne jedoch wirklich krank zu sein. In der Nase werden virulente Diphtheriebazillen gefunden. Eine Eigenart dieser leichten Nasenentzündung ist es, daß sie so oft chronisch wird, 
Wochen und Wochen bestehen bleibt, um plötzlich von selbst wieder zu verschwinden.

Man findet diese leichten Nasenentzündungen mit positivem Diphtheriebazillenbefund öfters bei unterernährten Säuglingen, wo sie epidemisch auftreten können (Blochmann, Conradi, Ballin, Seligmann, Silberschmidt u. a.). Ich selber hatte Gelegenheit, einen derartigen Fall bakteriologisch zu untersuchen. Ein Säugling, welcher Pneumonie, Pyelitis und Peritonitis hatte, aber einen ganz gesunden Rachen und eine gesunde Nase, sollte mit der Sonde ernährt werden, weil er alle Nahrung verweigerte. Nach einigen von diesen Sondenernährungen zeigte die Nase eine erhöhte Sekretion. Im Exsudat konnte ich Diphtheriebazillen nachweisen, welche auch im Rachen zu finden waren; die intrakutane Impfung beim Meerschweinchen ergab eine schwach positive Realktion, die Säureproduktion in der neutralen Glykose-Pepton-NaCl-Lackmuslösung war nach 24 Stunden deutlich positiv.

Wahrseheinlich war dieses Kind Diphtheriebazillenträger; das öftere Eindringen der Sonde durch die Nase hat vielleicht das Epithel geschädigt, die Schleimhautresistenz dadurch abgenommen, wodurch den Diphtheriebazillen gute Wachstumsbedingungen geboten wurden und sie ihre pathogene Wirkung entfalten konnten. Diphtheriebazillen wurden auch im Rachen gefunden, diese sehr empfindliche Schleimhaut erkrankte aber nicht.

Daß solche nicht als Diphtherie erkannten Ieichten Nasenkatarrhe öfters Veranlassung gegeben haben zu schweren Rachendiphtherien, ist wohl genïgend bekannt. Die Fälle von Seligmann, Cobbett, Burnett, Park und Beebe, Newsholme u. a. haben ja erwiesen, wie grob die Infektionsgefahr bei diesen leichten diphtherischen Nasenkatarrhen sein kann. Interessant ist es dabei, daß man fast immer den Zusammenhang zwischen diesen Katarrhen und einem Diphtheriefall nachweisen kann, und daß diese Fälle meistens erst zur bakteriologischen Untersuchung gekommen sind, weil stets neue Rachendiphtherie in der nächsten Umgebung vorkam, und man nicht wußte, woher die Infektion stammte.

Es ist darum dringend geboten, bei jeder Diphtheriebekämpfung genau auf dieseleichten Nasenkatarrhe zu achten.

\section{Das Vorkommen der Rhinitis fibrinosa.}

Im Gegensatz zur echten Nasendiphtherie bleibt die Rhinitis fibrinosa meistens in der Nase lokalisiert, der Rachen ist ganz frei. Braucht sie auch nicht allein von dem Diphtheriebacillus verursacht zu sein, so spielen doch oft die Diphtheriebazillen die ätiologische Rolle. Sie ist eine rein lokale krupöse Form der Nasendiphtherie und verläuft öfters 
chronisch. Nur die bakteriologische Untersuchung kann hier entscheiden, ob die Krankheit eine diphtherische ist oder nicht.

In der Literatur sind nur einige hundert Fälle bekannt.

Gerber untersuchte bakteriologisch 40 Fälle von Rhinitis

fibrinosa und fand Diphtheriebazillen bei . . . . . 72.5 Proz.

Meyer untersuchte 22 Fïlle und fand Diphtheriebazillen bei $59 \cdot 0$,"

Scheller untersuchte 39 Fälle und fand Diphtheriebazillen bei $56 \cdot 0$,",

Ravenel untersuchte 41 Fälle und fand Diphtheriebazillen bei $82 \cdot 0$,,

Durchschnittlich sind also 66.0 Prozent der Fälle von Rhinitis fibrinosa diphtherisch; die anderen werden von Staphylo-, Strepto- und Pneumokokken verursacht.

tber die Ätiologie dieser Krankheit gehen die Meinungen noch sehr auseinander. Einige Forscher meinen, daß, wenn typische Diphtheriebazillen sich vorfinden, diese Schleimhautentzündung durch die pathogene Wirkung dieses Bacillus verursacht wird. Andere Untersucher sind der Meinung, daß in dergleichen Fällen die Diphtheriebazillen als zufällige Schmarotzer anwesend sind (das Kind also Diphtheriebazillenträger ist).

Durch irgendwelchen Umstand sei die Nasenșchleimhaut erkrankt, und die Diphtheriebazillen würden neben den natürlichen Saprophyten gefunden, ohne dab sie als die alleinige Ursache dieser Entzündung anzusehen seien. Welcher Meinung man auch zustimmen möge, so ist doch genügend bekannt, daß diese Krankheit wegen ihres milden Verlaufes zwar klinisch keine große Bedeutung hat, epidemiologisch aber desto mehr. Diese Fälle haben öfters schon Veranlassung gegeben zu neuen Fällen von Rhinitis fibrinosa und typischen schweren Rachendiphtherien (Dowson, Ravenel, Abbott, Concetti, Neumann). Gerade das Verbleiben auf der Nasenschleimhaut macht, daß man diese Diphtheriebazillen als die resistentesten Formen ihrer Art zu betrachten hat. Begreiflich ist es, daß die Diphtheriebazillen durch ihr großes Anpassungsvermögen an weniger gute Nährverhältnisse, wozu auch die Nasenschleimhaut zu rechnen ist, diese Krankheit zu einer chronischen machen, weil sie, wenn sie hier einmal eingewöhnt sind, nicht so schnell verschwinden werden. Dadurch eben sind diese chronischen diphtherischen Nasenentziundungen epidemiologisch so sehr zu fürchten.

Wie es zu erklären ist, daß die Nasenentzündungen, bei denen Diphtheriebazillen die ätiologische Rolle spielen, so außerordentlich mild und gutartig verlaufen, ist nicht bekannt. Ob die Nasenschleimhaut das Diphtherietoxin schlecht zu resorbieren vermag, oder ob der Nasenschleim 
(das Mucin) spezielle noch unbekannte antitoxisch-bakterizide Eigenschaften hat, oder das mehrschichtige Flimmerepithel, das im Pharynx nicht zu finden ist, eine gewisse Rolle spielt, wissen wir nicht.

Das häufige Erkranken der Nase hier in Holland unter dem Bilde eines Schnupfens, was auch stark beeinflußt wird durch das sehr wechselnde Klima, erweckt jedenfalls den Eindruck, daß die Nasenschleimhaut gar nicht immer imstande ist, einer Infektion entgegenzutreten. An dem ziemlich seltenen Auftreten der diphtherischen Nasenentzündung ist wohl die Beschaffenheit der Nasenmukosa nicht allein Schuld.

Meines Erachtens hat man hier vier Momente, welche ein eventuelles Zustandekommen einer Nasendiphtherie sehr beeinflussen können:

1. Die geringe Affinität des Diphtheriebacillus zur Nasenschleimhaut, weil sie ihm schlechte Lebensbedingungen bietet.

2. Die Intensität der antiinfektiösen-antitoxischen Kraft der Nasenschleimhaut und des Sekrets, welche mehr oder weniger hemmend auf den Diphtheriebacillus wirken kann (lokale Prädisposition).

3. Die Virulenz und Resistenz der betreffenden Diphtheriebazillen.

4. Die mehr oder weniger große körperliche Prädisposition.

Es wird natürlich von dem Gleichgewicht zwischen diesen Faktoren abhängen, ob eine eventuelle Naseninfektion durch Diphtheriebazillen stattfinden kann.

Baginsky gibt davon ein schönes Beispiel. Bei den 525 klinisch sehr genau beschriebenen Diphtheriefällen hat er zeigen können, daß die Intensität der Krankheit, die Schwere der Racheninfektion parallel geht mit dem Auftreten von Nasendiphtherie und letalem Ausgang:

Unter 193 Fällen von einf acher

$$
\text { Nasendiphtherie : Todesfälle }
$$

lokalisierter Diphtherie (ziemlich leichtes Krankheitsbild, niedriges Fieber usw.) Unter 361 Fällen von allge. mein toxischer Diphtherie (hohes Fieber mit Erkrankung des gesamten Organismus) ...... Unter 29, Fällen von sep44 Fälle $=12 \cdot 1 \quad, \quad 56 \quad,=15 \cdot 5 \quad$, tischer Diphtherie (sehr schweres Krankheitsbild mit Erkrankung des gesamten Organismus, Gangrän) . . $11,=38.0 " 26 \quad=90.0$ "

Vielleicht daß es sich bei der Rhinitis fibrinosa und den ganz leichten chronischen diphtherischen Coryzae, bei ganz intakter, gesunder Rachen- 
schleimhaut um eine lokale Herabsetzung der Schleimhautimmunität in dem Wrightschen Sinne handelt, wie bei Furunkulose, lokalen Abszessen, Fisteln usw.

Resümierend können wir also sagen:

Das keineswegs regelmäßige Erkranken der Nase bei der gewöhnlichen Rachendiphtherie, das seltene Vorkommen der primären akuten Nasendiphtherie und der gutartige milde Verlauf der diphtherischen lokal-krupösen, oft chronisch verlaufenden Rhinitis fibrinosa, der Coryzae und leichten Rhinitiden liefern uns den Beweis, daß der Diphtheriebacillus kein gewöhnlicher Gast der Nasenschleimhaut ist und seine pathogenen Eigenschaften bei weitem besser auf der Rachenschleimhaut entfalten kann.

Der Klebs-Loefflersche Diphtheriebacillus hat eine viel größere Affinität zur Rachenschleimhaut als zur Nasenschleimhaut.

Im allgemeinen darf man sagen: Je weiter vom Rachen entfernt, desto seltener zeigen sich die diphtherischen Entzündungen.

Scheller fand von 887 Diphtheriefällen 91 -3 Prozent Rachendiphtherie, 2 Prozent Nasendiphtherie und nur 1 mal diphtherische Konjunktivitis; Cohn auf 1000 Diphtheriefälle nur 2 mal eine diphtherische Konjunktivitis, 1 mal Diphtherie des Gehörganges, 1 mal Wunddiphtherie usw.

Baginsky von 525 Diphtheriefällen, wovon 100 Prozent Rachendiphtherie, nur bei 3 Fällen eine diphtherische Konjunktivitis.

\section{Die Klebs-Loefflersehen Diphtheriebazillen nach der klinischen Heilung des Diphtheriekranken.}

Roux und Yersin haben zuerst 1890 darauf hingewiesen, daß die Diphtheriebazillen mit der Heilung des diphtherischen Prozesses nicht sogleich verschwinden,' sondern nach dem Verschwinden der Pseudomembran noch 2 Wochen auf der Rachenschleimhaut verbleiben können. Dies wurde kurz darauf zuerst von Escherich, Loeffler und Abel bestätigt, und später sind noch unendlich viele Untersuchungen dazu gekommen, welche gleiche Befunde ergaben.

Loeffler gebührt wieder das große Verdienst, daß er diesen Befund sofort zur Diphtheriebekämpfung herangezogen hat, indem er 1894 auf dem 8. Internationalen Kongreß für Hygiene und Demographie in Budapest den Antrag stellte, daß Diphtherierekonvaleszenten nicht eher zum freien Verkehr mit anderen zurückkehren dürfen, bevor es bakteriologisch festgestellt worden ist, daß die Diphtheriebazillen völlig verschwunden sind. 
Daß die Diphtherie eine ziemlich leicht zu bekämpfende Krankheit ist, muß wohl an erster Stelle dem Umstande zugeschrieben werden, daß, wie ich schon im Kapitel 3 ausgeführt habe, der Diphtheriebacillus viel mehr zu den obligaten Parasiten gehört denn zu den fakultativen, daß er wegen seiner hohen Ansprüche an Nahrung usw. ziemlich schwer ein saprophytisches Leben führen kann.

Folgende Statistiken dürften das noch weiter beweisen:

Kolle untersuchte 750 Diphtheriefälle so lange, bis keine Diphtheriebazillen mehr gefunden wurden. Es verschwanden die Bac. diphtheriae:

Bei 325 Fällen nach 3 Tagen

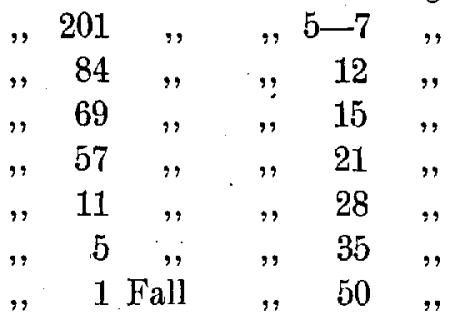

Scheller fand bei 339 Diphtheriefällen, daß die Diphtheriebazillen nachweisbar waren:

Unter 10 Tagen bei 75 Personen.

$\begin{array}{lrllrl}" & 11 & , & , & 264 & , \\ " & 21 & , & , & 119 & " \\ " & 31 & , & , & 62 & , \\ " & 41 & , & , & 35 & " \\ " & 51 & , & " & 26 & " \\ " & 61 & , & , & 18 & " \\ , & 90 & , & , & 8 & .,\end{array}$

von Drigalsky, welcher über die Diphtherie in Halle Erfahrung hat, fand unter 2800 Fällen nur bei 6 Diphtheriebazillen noch nach 4 Wochen im Rachen.

Tjaden fand, daß unter 1338 Diphtheriefällen in Bremen

33 Prozent nach 2 Wochen

$25 \quad, \quad, 3 \quad, \quad$,

$10 \quad, \quad, 5 \quad$ "

keine Bac. diphtheriae mehr hatten.

Otto sah die Diphtheriebazillen verschwinden

bei 45 Prozent nach 4 Tagen

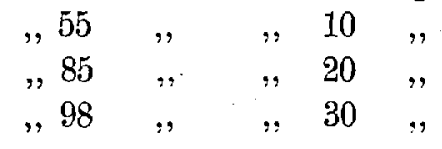


Büsing fand unter 2063 Fällen, welche er untersuchte, bis keine Diphtheriebazillen 'mehr gefunden wurden,

55 Prozent nach 2 Wochen

70

frei von Bac. diphtheriae.

Ich selber sah auch meistens die Diphtheriebazillen nach 2 oder 3 Wochen verschwinden.

Die Zahlen von diesen verschiedenen Statistiken stimmen also ziemlich gut überein. - Durchsehnittlich versehwinden die Diphtheriebazillen nach 2 bis 3 Wochen nach dem Ausbruch der Krankheit.

Aus diesen Zahlen tritt also deutlich hervor, was Beck schon 1890 am infizierten Tiere hat beweisen können, daß der Diphtheriebacillus auf der ganz intakten Schleimhaut kaum imstande ist zu leben.

2/3 der Diphtheriekranken verlieren die Diphtheriebazillen, wenn die Pseudomembranen verschwinden, die Schleimhaut in Heilung uibergeht, das Epithel sich regeneriert, und die Flora wieder zu normalen Verhältnissen zurückkehrt. . Das übrige $1 / 3$ der Diphtheriekranken braucht längere Zeit, um sich selbst zu desinfizieren, 6 Wochen, 2 Monate, und dann sind noch äußerst hartnäckige Fälle bekannt, wo sich die Diphtheriebazillen mehrere Monate bis ein Jahr mit voller Virulenz hielten, trotz Mundspülungen und Insufflationen mit allen möglichen Antiseptica (Seligmann, Prip, Schäfer u. a.). Daß bei solchen Fällen mehrere Faktoren zusammenarbeiten müssen, um dies zu ermöglichen (individuelle. Prädisposition, lokale Prädisposition, erhöhte Resistenz der Diphtheriebazillen) ist wohl wahrscheinlich (siehe noch Seite 54).

Obwohl die Diphtheriebazillen hier auch am häufigsten auf der Rachenschleimhaut zurückbleiben, kann es uns doch nicht wundern, daß solche resistentere Bazillenformen auch auf der für die Diphtheriebazillen weniger gïnstigen Nasenschleimhaut verbleiben, und wenn sie einmal durch ihr Anpassungsvermögen an sie gewöhnt sind, auch da lange verbleiben können.

Wahrscheinlich ist, wie Wolff und Mallory am Sektionstisch haben feststellen können, daß die Diphtheriebazillen, welche in der Nasenhöhle zurückbleiben, aus den Nasennebenhöhlen (Antrum Highmori usw.) stammen, welche bei Diphtherie ja öfters mit erkranken. Die Diphtheriebazillen bleiben in diesen tiefen Höhlen zurück und kommen dann und wann schubweise wieder in der Nasenhöhle zum Vorsehein, wie bei der Meningitis cerebrospinalis (Weichselbaum). Man wird dies also am meisten zu erwarten haben bei den geheilten Fällen von allgemeintoxischer 
und septischer Diphtherie, wo sich eben die Nasenerkrankung (Nebenhöhlenerkrankung) am häufigsten zeigt.

Die Untersuchungen Bonhoffs sind in diesem Verbande sehr interessant. Während er nur bei 0.95 Prozent allein Diphtheriebazillen im Blute hat nachweisen können, hat er sie bei 53 Prozent in der Zerebrospinalflüssigkeit, wenn auch sehr spärlich, auffinden können. Es ist denn auch sehr wahrscheinlich, daß die Diphtheriebazillen via der Nase (Lamina cribrosa) in die Spinalflüssigkeit hineingelangten, weil bei diesen schweren Fällen eine sehr hohe Zahl von schwerer Nasendiphtherie bestand, nämlich 66 Prozent.

Ich selbst sah bei drei geheilten Rachendiphtherien die Diphtheriebazillen nur in der Nase zurïckbleiben, und die Fälle Wolffs und Pughs, Dowson u. a. liefern wohl den größten Beweis, wie notwendig es eben ist, bei jeder Untersuchung eines Diphtherierekonvaleszenten die Nasenuntersuchung nicht zu unterlassen. Viele gibt es noch, welche die Nasenuntersuchung von Rekonvaleszenten und gesunden Bazillenträgern vernachlässigen; die Diphtherie sei eine typische Rachenkrankheit, und die Nase habe damit nichts zu schaffen. Es ist auffallend, wie wenig man in der Literatur Angaben. von Nasenuntersuchungen auf Diphtheriebazillen findet. Meine Erfahrung geht dahin, daß die Nasenuntersuchung yon ebenso großer Wichtigkeit ist, wie diejenige der Rachenschleimhaut. Aus den neulichen Untersuchungen Schürmanns geht das wohl am deutlichsten hervor (Seite 60 und Kapitel 11).

Selbstverständlich ist, daß bei der. Rhinitis fibrinosa und all den anderen diphtherischen Nasenentzündungen die Diphtheriebazillen nach der klinischen Heilung besonders auf der Nasenschleimhaut zurückbleiben werden.

\section{\%. Die Klebs-Loefflerschen Bazillen bei denjenigen, welehe mit Diphtherie in Berii hrung gekommen sind (die gesunden Bazillen- träger, Diphtheriekontakte).}

Der Befund Loefflers, kurz nach der Entdeckung des Diphtheriebacillus, wo er bei einem ganz Gesunden virulente Diphtheriebazillen auf der Rachenschleimhaut antraf, was ihn selbst zu Zweifeln an der ätiologischen Bedeutung des Diphtheriebacillus gebracht hat, wurde durch den Befund von Roux, Escherich u. a. bei Diphtherierekonvaleszenten bestätigt, wo es sich eben zeigte, daß Diphtheriebazillen sich auch auf den Schleimhäuten ganz Gesunder aufhalten können.

Uber die Frequenz dieser „Bazillenträger" hat Loeffler zuerst Zahlen 
geben können. Während einer Schulepidemie in Greifswald 1894 wurden von ihm und Abel-160 gesunde Kinder bakteriologisch untersucht, von denen sich 4 als Diphtheriebazillenträger zeigten. Im Jahre 1897 hat Fibiger auf glänzende Weise gezeigt, daß er eine bis dahin stets wiederkehrende Diphtherieepidemie in einem Gymnasium in Herlufsholm mit vollem Erfolge hat bekämpfen können durch Aufspüren und Isolieren der gesunden Diphtheriebazillenträger. Seitdem ist überall die große epidemiologische Bedeutung dieser gesunden Bazillenträger zutage getreten, und jene Bekämpfungsmethode mit den besten Resultaten befolgt worden. Jetzt gibt es wohl kaum jemand mehr, der nicht davon überzeugt ist, daß die Desinfektion von Räumen, in denen die Diphtheriekranken während der Inkubationszeit und Krankheit sich aufhielten, von Gegenständen usw. nutzlos ist, wenn nicht vor allem die Keimträger, die lebendigen Infektionsquellen, isoliert werden. Was im vorigen Kapitel über das Verschwinden der Diphtheriebazillen bei Rekonvaleszenten gesagt wurde, gilt auch für den gesunden Bazillenträger.

Die Statistik Ottos, der zugleich mit den Rekonvaleszenten die gesunden Diphtheriekontakte untersuchte, gibt ein schönes Beispiel dafür, daß die Verhältnisse bei beiden demselben Gesetze unterworfen sind.

Unter 68 Diphtheriebazillenträgern waren frei von Diphtheriebazillen: 37 Prozent nach 2 Tagen

$.53 \quad, \quad, 4 \quad 4$

$84,, \quad, 20$,"

Daß bei sogenannten „Dauerausscheidern“, auch bei den ganz gesunden Diphtheriekontakte vorkommen können, ist aus der Literatur geniugend bekannt (Lehrer in Schulen, Pflegerinnen in Spitälern usw.). Solche ganz gesunden Keimträger sind natürlich am gefährlichsten da, wo sie mit vielen anderen, besonders Kindern zusammenleben (Schulen, Anstalten, Krankenhäuser usw.). Man sieht dann oft die Epidemien erst aufhören, wenn solche hartnäckigen Keimträger isoliert werden.

Wie eben die Beschaffenheit der Schleimhaut einen großen Einfluß auf das Haftenbleiben der Diphtheriebazillen bei den gesunden Diphtheriekontakten ausübt, möge die interessante Statistik der Diphtheriestation in Breslau zeigen: Unter 139 Personen mit anormaler Rachenschleimhaut, welche mit Diphtherie in Berührung gekommen waren, wurden bei 70 Prozent Diphtheriebazillen gefunden; unter denjenigen mit ganz gesunden Schleimhäuten nur bei 8 bis 10 Prozent.

Goadby untersuchte 100 gesunde Schulkinder; bei 42 Kindern mit anormaler Pharynxschleimhaut wurden 14 mal Diphtheriebazillen ge- 
funden $=34$ Prozent; bei den übrigen 58 Kindern mit gesunden Schleimhäuten nur $4 \mathrm{mal}=7$ Prozent.

Wenn wir unsere Aufmerksamkeit auf die große Kategorie der gesunden Diphtheriebazillenträger lenken, so ist es auffallend, wie groß der Parallelismus ist zwischen den Keimträgern und den Diphtheriekranken, mit anderen Worten, je inniger der Kontakt mit dem Diphtheriekranken, desto häufiger werden die Diphtheriebazillen auf gesunde Schleimhäute verpflanzt.

Ich habe versucht, darüber einige Klarheit zu erlangen. Aus den ungeheueren Mengen von Untersuchungen werde ich hier nur die ,zuverlässigsten" verwerten, bei denen nicht allein der morphologische Befund, sondern auch entweder Säureproduktion aus Glykose oder Vịulenzprüfung die Diagnose Diphtheriebacillus bestätigt haben.

Um den strengen Parallelismus zwischen Diphtheriekranken und Bazillenträgern nachzuweisen, möchte ich die Diphtheriebazillenträger in 5 verschiedene Kategorien einteilen, je nach der Innigkeit des Kontaktes mit Diphtherie.

a. Kategorie I umfaßt die nächsten Verwandten des Diphtheriekranken, also Eltern und Geschwister.

Cobbett untersuchte alle Mitglieder einer Familie (9 Personen) und fand Bac. diphtheriae bei . . . . . . 100.0 Proz.

Park untersuchte alle Mitglieder einer Familie (4 Personen)

und fand Bac. diphtheriae bei ... . . . . . 100.0 ",

Scheller in 3 Familien mit 16 Personen Bac. diphtheriae bei 87.5 ",

Park und Beebe in 14 infizierten Familien mit 48 Personen

Bac. diphtheriae bei ... . . . . . . 50. 50 ",

Williams in einer infizierten Familie mit 5 Personen Bac.

diphtheriae bei .......... . . 60.0 ",

Spirig in 2 Familien mit 9 Personen Bac. diphtheriae bei $66 \cdot 6$ ",

Durchschnittliche Prozentzahl . . . . . . . 66.0 "

In anderen Familien, wo die Isolierung des Kranken gründlich vorgenommen wurde, Bac. diphtheriae nur bei 10 Prozent der Hausgenossen.

b. Kategorie II umfaßt diejenigen, welche "in Krankenhäusern oder Anstalten Diphtheriekranke behandeln und pflegen, also Ärzte, Krankenschwestern und Studenten.

Richmond und Salter untersuchten den Rachenschleim

von 29 Ärzten, Pflegerinnen und Studenten und fanden Bac.

diphtheriae bei ............. . . 48.0 Proz.

Seligmann unter 27 Pflegerinnen Bac. diphtheriae bei . . 40.0 ", 
Lippmann unter 250 vom Personal eines Krankenhauses Bac. diphtheriae bei . . . . . . . . 50.0 Proz. Pugh unter 56 Krankenschwestern Bac. diphtheriae bei 12.5 ", Ritter unter 18 Personen, welche Diphtheriekranke pflegten, Bac. diphtheriae bei ............. 11. . . "

Fibiger unter 53 Personen des Krankenhauspersonales Bac. diphtheriae bei ............. 6. 6. 6.0, Durchschnittliche Prozentzahl . . . . . . . . 37-0 ,

c. Kategorie III umfaßt Bewohner von Kasernen und Pensionaten, also Militär und Schüler.

Peck unter 100 Schülern eines Pensionates Bac. diphtheriae bei ............. 31. . 310 Proz.

Gabrischewsky unter 66 gesunden Kindern eines Pensionates Bac. diphtheriae bei . . . . . . . . 31.5 ",

Arkwright unter 537 Knaben einer Militärschule (Duke of York school) Bac. diphtheriae bei . . . . . . . . . . diphtheriae bei . . . . . . . . . . . . . . . . . . . Stockholm Bac. diphtheriae bei . . . . . . . . $19 \cdot 0$, Otto in einer Kaserne Bac. diphtheriae bei . . . . . 34.0 ", Roussel und Malard unter 78 Gesunden aus der Kaserne des 2. Reg. d'artillerie coloniale Bac. diphtheriae bei. . . $32 \cdot 0$ ", Durchschnittliche Prozentzahl . . . . . . . . . 23.0 ",

d. Kategorie IV umfaßt Personen, welche in Krankenhäusern oder Spitälern mit Diphtheriekranken zusammen gepflegt wurden, selbst aber gesunde Rachen und Nasen hatten.

In dem Bethany House (Minnesota Board of Health 1900), wo 3 Diphtheriefälle vorgekommen waren, wurden unter den 69 Bewohnern Bac. diphtheriae gefunden bei . . . :

Müller untersuchte systematisch 100 Kinder in einem Krankensaal der Heubnerschen Klinik. Bei der ersten Untersuchung fand er bei 4 Kindern Bac. diphtheriae. Später kamen 6 neu aufgenommene Kinder hinzu; 14 Kinder bekamen jetzt während ihres Aufenthaltes auf dem Saal Bac. diphtheriae im Rachen, also im ganzen Bac. diphtheriae bei . . . . . . . . . . . . . . Müller sah, daß die Infektion von Kind zu Kind weiterging. Hieraus ist auch wieder zu ersehen, wie unbemerkt die 
Diphtherie durch nicht an dieser Krankheit leidende Kinder in ein Krankenhaus eingeführt werden kann.

Graham Smith fand unter 48 Patienten und Pflegerinnen eines Krankensaales Bac. diphtheriae bei . . . . . . 12.0 Proz.

Büsing fand unter 42 Patienten eines Krankensaales Bac. diphtheriae bei ............

Johannessen fand bei einer Untersuchung von 38 Patienten eines Krankensaales Bac. diphteriae bei

$12 \cdot 0$

Park und Beebe untersuchten 55 Kinder in dem New York

Foundling Hospital und fanden Bac. diphtheriae bei . . 10.0 ",

Seligmann in einer Idiotenanstalt, wo immer Diphtherie auftrat, unter 126 Versuchen Bac. Diphtheriae bei. . . 10.0 "

Durchschnittliche Prozentzahl . . . . . . . 14.0 ",

e. Kategorie $\mathbf{V}$ umfaßt die gesunden Schulkinder, welche die mit Diphtherie infizierten Schulen besuchen.

Crowley und Erich untersuchten die Rachenschleimhaut von 93 Lehrern und Kindern einer Klasse, wo nicht weniger als 80 Diphtheriefälle vorgekommen waren, und fanden Bac. diphtheriae bei

$45 \cdot 0$ Proz.

Denny bei 190 Knaben einer Zuchtschule, wo 10 Diphtheriefälle vorgekommen waren, Bac. diphtheriae bei . . . . .

Graham Smith bei einer Schulepidemie in Colchester unter 519 untersuchten gesunden Kindern Bac. diphtheriae bei

Tomas bei 29 Schulepidemien Bac. diphtheriae bei : . . .

Ustvedt untersuchte 3 Schulen mit 4211 Kindern und fand Bac. diphtheriae bei . . . . . . . . . . .

Loeffler und Abel unter 160 Schulkindern Bac. diphtheriae bei . . . . . . . . . . . . .

Leegaard unter 341 Knaben aus 4 Klassen Bac. diphtheriae bei

Geirsvold unter 967 Schülern Bac. diphtheriae bei

Lomry untersuchte 32 Sehulen in 2146 Einzeluntersuchungen im belgischen Luxemburg und fand Bac. diphtheriae bei Durchschnittliche Prozentzahl

$9 \cdot 0$,

$10 \cdot 4$, $7 \cdot 5$ " $4 \cdot 5$, $2 \cdot 5$ $2 \cdot 0 \quad$, $9 \cdot 0 \quad$, $6 \cdot 6 \quad$, $7 \cdot 0$

Wenn wir die Zahlen dieser letzten Kategorie prüfen, so sehen wir, daß Crowley und Erich eine sehr hohe Prozentzahl fanden, nämlich 45.0 Prozent, aber es waren auch nicht weniger als 80 Diphtheriefälle vorgekommen. Bei den anderen Untersuchern, wo die Prozentzahl zwischen 2.5 und 10 Prozent schwankt, ist die Zahl der vorgekommenen Diphtherie- 
fälle auch bedeutend niedriger. Es besteht denn auch ein direkter $\mathrm{Zu}$ sammenhang zwischen der Anzahl Diphtheriekranker und der Anzahl Bazillenträger.

Folgende Beispiele dürften diesen strengen Parallelismus noch viel deutlicher beleuchten.

Seligmann untersuchte bakteriologisch eine Anzahl Säuglinge, welche in verschiedenen Säuglingsstationen eines Kinderkrankenhauses gepflegt wurden, und fand folgende Zahlen:

Säuglingshaus II 1 Diphtheriefall und 1 Diphtheriebazillenträger

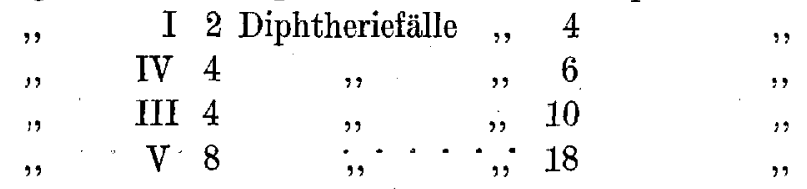

Frank in einer Mädchenschule:

$\begin{array}{lrcccc}\text { Januar } & 11 & \text { Bazillenträger } & 11 & \text { neue } & \text { Diphtheriefälle } \\ \text { Februar } & 13 & , & 8 & , & , \\ \text { März } & 3 & , & 0 & , & , \\ \text { April } & 8 & , & 1 & , & ,\end{array}$

Wenn wir die Untersuchung von Crowley und Erich also nicht mitrechnen, weil sie nicht das natürliche Schulverhältnis darstellt, so ist die Durchschnittsprozentzahl für die normalen Schulkinder 7·0 Prozent.

Vergleichen wir jetzt alle Durchschnittsprozentzahlen miteinander, so fällt die starke konstante Abnahme sofort auf, welche in unmittelbarem Zusammenhang steht mit der Innigkeit des Kontaktes mit den Diphtheriekranken:

66.0 Proz. gesunde Diphtheriebazillenträger unter denjenigen, welche in unmittelbarer Nähe des Diphtheriekranken sich aufhalten (Eltern und Geschwister).

37·0 . , gesunde Diphtheriebazillenträger unter denjenigen, welche Diphtheriekranke behandeln und pflegen (Ärzte, Pflegerinnen, Studenten).

23.0 „, gesunde Diphtheriebazillenträger unter denjenigen, welche Kasernen und Pensionate bewohnen.

14.0 , gesunde Diphtheriebazillenträger unter denjenigen, welche in Krankenhäusern und Anstalten zugleich mit Diphtheriekranken gepflegt werden.

7.0 , gesunde Diphtheriebazillenträger unter Schulkindern, welche die mit Diphtherie infizierte Schule besuchen (siehe Fig. 1). 
Die Prozentzahl ist also am niedrigsten bei den Schulkindern, und das läßt sich auch gut verstehen. Durch die permanente Aufsicht der Lehrer ist der Kontakt zwischen den Schülern nicht innig genug, daß die Diphtheriebazillen leicht weiter verbreitet werden können. Es ist denn auch sehr wahrscheinlich, wie Stokvis, Ustvedt, von Drigalsky, Angus Me Donald u. a. meinen, daß die Diphtherie vielmehr als eine „Hausinfektion" denn als eine Schulinfektion zu betrachten ist. Doch kann die Schule eine große Infektionsquèlle bieten, wenn die Diphtheriefälle und Bazillenträger nicht sofort erkannt und isoliert werden.

Interessant ist die Prozentzahl der Kasernenbewohner und Pensionate, wenn wir sie denjenigen der Schule gegenüberstellen. Nur das Zusammenschlafen und die gemeinschaftlichen Mahlzeiten (verringerter Kontakt) machen, daß hier die Zahl der Bazillenträger sofort in die Höhe getrieben wird. Das Beispiel Tjadens ist in diesem Verbande zu schlagend, um es hier nicht zu erwähnen. Tjaden wollte in Familien, in denen Diphtherie vorgekommen war, feststellen, welche Personen die höchste Prozentzahl an Diphtheriebazillenträgern aufwiesen, und fand:

bei den Müttern . . . . . . . . 15.5 Proz. Bazillenträger

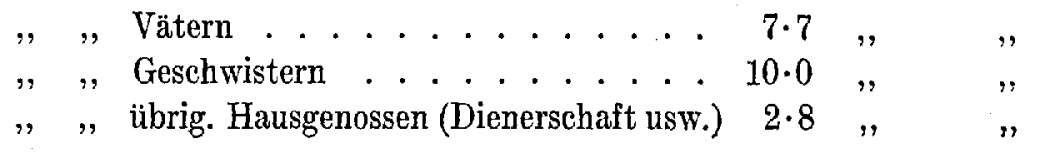

Auch hier ist sofort zu ersehen, daß diejenigen, welche in unmittelbarer Nähe der Kranken verweilen, die höchsten Zahlen geben.

Der strenge Parallelismus zwischen Anzahl von Diphtheriebazillenträgern und Diphtheriekranken macht die folgende Schlußfolgerung berechtigt:

Je inniger der Kontakt mit dem Diphtheriekranken, desto mehr Diphtheriebazillenträger.

Soweit ich weif, sind die Untersuchungen dieses Kapitels alle an der Rachenschleimhaut vorgenommen; die Nasenuntersuchung ist auch hier wieder nicht in Betracht gekommen.

Pugh gibt uns jedoch ein Beispiel von einem Kinde, das Diphtheriebazillen nur in der Nase hatte, selbst völlig gesund war, dessen 2 Schwestern aber an Rachendiphtherie litten.

Van Riemsdyk sah bei einem gesunden Lehrer virulente Diphtheriebazillen nur in der Nase; in seiner Schule waren Diphtheriefälle vorgekommen. 
Trump fand bei einer Hausinfektion Diphtheriebazillen mehr in der Nase als im Rachen.

Graham Smith gibt in seiner Monographie eine Statistik von Fällen, wo bei gleichzeitiger Untersuchung der Nasen- und Rachenhöhle allein die Nase mit Diphtheriebazillen infiziert gefunden wurde. Nach diesen Angaben hatten 6.3 Prozent ger gesamten Diphtheriekontakte und 1.9 Prozent der Schulkinder nur infizierte Nasen.

Schürmann gibt folgende Zahlen von 8885 Diphtherieuntersuchungen aus dem Untersuchungsamte für ansteckende Krankheiten in Halle:

Unter 1068 Nasensekretproben wurden bei 17 Prozent virulente Diphtheriebazillen gefunden.

Unter 7770 Rachensekretproben wurden bei 21 Prozent virulente Diphtheriebazillen gefunden.

- Obwohl auch hier wieder deutlich die Prädilektion der Diphtheriebazillen für den Pharynx zutage tritt, wird man doch nie die Nasenuntersuchung unterlassen dürfen, weil es eben bei Diphtheriekontakten darauf ankommt, Bazillenträger aufusuchen, und man im voraus nicht wissen kann, ob man es nicht mit einem Nasendauerausscheider zu tun hat.

\section{Das Yorkommen von Klebs-Loefflerschen Bazillen bei Ge- sunden, welche nicht mit Diphtherie in Berïhrung gekommen sind.}

Die Zahlen, welche hierüber publiziert sind, gehen weit auseinander, und das ist wohl dem Umstande zuzuschreiben, da $B$ die Nachfrage, ob die betreffenden Personen wirklich nicht'mit Diphtherie in Berührung gekommen sind, nicht mit genügender Zuverlässigkeit geschehen ist.

Ich will hier also nur solche Untersuchungen erwähnen, von denen man in jeder Hinsicht sagen kann, daß sie-gewissenhaft vorgenommen sind.

Kober, der sich selbst über die außerordentlich hohen Zahlen

der anderen Untersucher wunderte, untersuchte 600 normale Schulkinder aus Breslau, bei denen ein Diphtheriekontakt nicht nachgewiesen werden konnte, und fand Bac. diphtheriae bei . . . . . . . . . . . 0.83 Proz.

Graham Smith untersuchte 362 Personen und fand Bac. diphtheriae bei . . . . . . . . . . 0.27 "

Park und Beebe in New York untersuchten 830 Personen und fanden Bac. diphtheriae bei ........ 0.6 , 
Der Massachusetts Board of Health untersuchte in Providence 927 Nichtkontakte und fand Bac. diphtheriae bei . . . . . . . . . . . . 0.3 Proz.

Scheller gelegentlich einer Massenuntersuchung Bac. diphtheriae bei . . . . . . . . . . . 0.0 , Joh. Fibiger unter 82 Nich tkontakten Bac. diphtheriae bei 0.0 , Cobbett unter 43 nicht kontakten Schulkindern Bac. diphtheriae bei . . . . . . . . . . . .

Lomry ,en dehors de tout cas de Diphtherie depuis plusieurs $0 \cdot 0 \quad$, années" (La Diphthérie dans le Luxembourg belge) Bac.

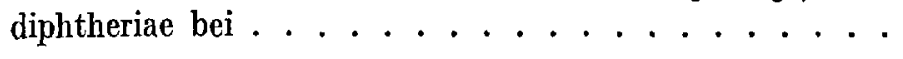
$0 \cdot 0 \quad$,

Für Dörfer, wo jeder Kontakt mit Diphtherie ausgeschlossen werden konnte, weil in den letzten 8 bis 10 Jahren kein einziger Fall von Diphtherie oder verdächtiger Angina vorgekommen war, fand ich folgende. Zahlen:

Stokvis und van Riems dyk unter 50 Kindern aus der Voluwe und Limburg (Holland) Bac. diphtheriae bei . . . . . 0.0 Proz. Steenmeyer in Schelluinen (Holland) Bac. diphtheriae bei 0.0 " Ustvedt in Norwegen, Bac. diphtheriae bei ...... . 0.0 , Cobbett unter 90 Knaben einer Zuchtschule, in der seit mehreren Jahren kein einziger Diphtheriefall vorgekommen war, Bac. diphtheriae bei . . . . . . . . 0. 0 ", Roux und Yersin in einem Seedorf Caën, wo in den letzten

Zeiten kein einziger Diphtheriefall vorgekommen war, Bac. diphtheriea bei . . . . . . . . . . 0. $0.0 "$

In den Großstädten sehen wir also doch noch einige Fälle mit positivem Diphtheriebazillenbefund; dies kann uns aber gar nicht wundern; denn in einer Grobstadt, wo es immer Diphtherie gibt, ist es außerordentich schwer zu wissen, ob jemand mit Diphtheriebazillen in Berührung gekommen ist oder nicht. Wir denken dabei sofort an die ganz-leichten diphtherischen Anginae, welche entweder ganz übersehen oder doch nicht als diphtherisch angesehen werden, und an die gesunden Bazillenträger, mit denen man vielleicht öfters in Berührung kommt, ohne es zu wissen.

In Dörfern, wo in den letzten Jahren kein einziger Diphtheriefall oder verdächtige Angina vorgekommen ist, und wo selbstverständlich, infolge des geringen Außenverkehrs der Bewohner, gar nicht einmal zu reden von den Kindern, jeder Kontakt mit Diphtherie mit größter Sicherheit aususchließen ist, sehen wir keinen einzigen Diphtheriebazillenträger. Statt also den Parallelismus zwischen Bac. diphtheriae 


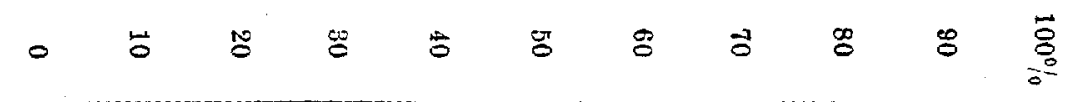

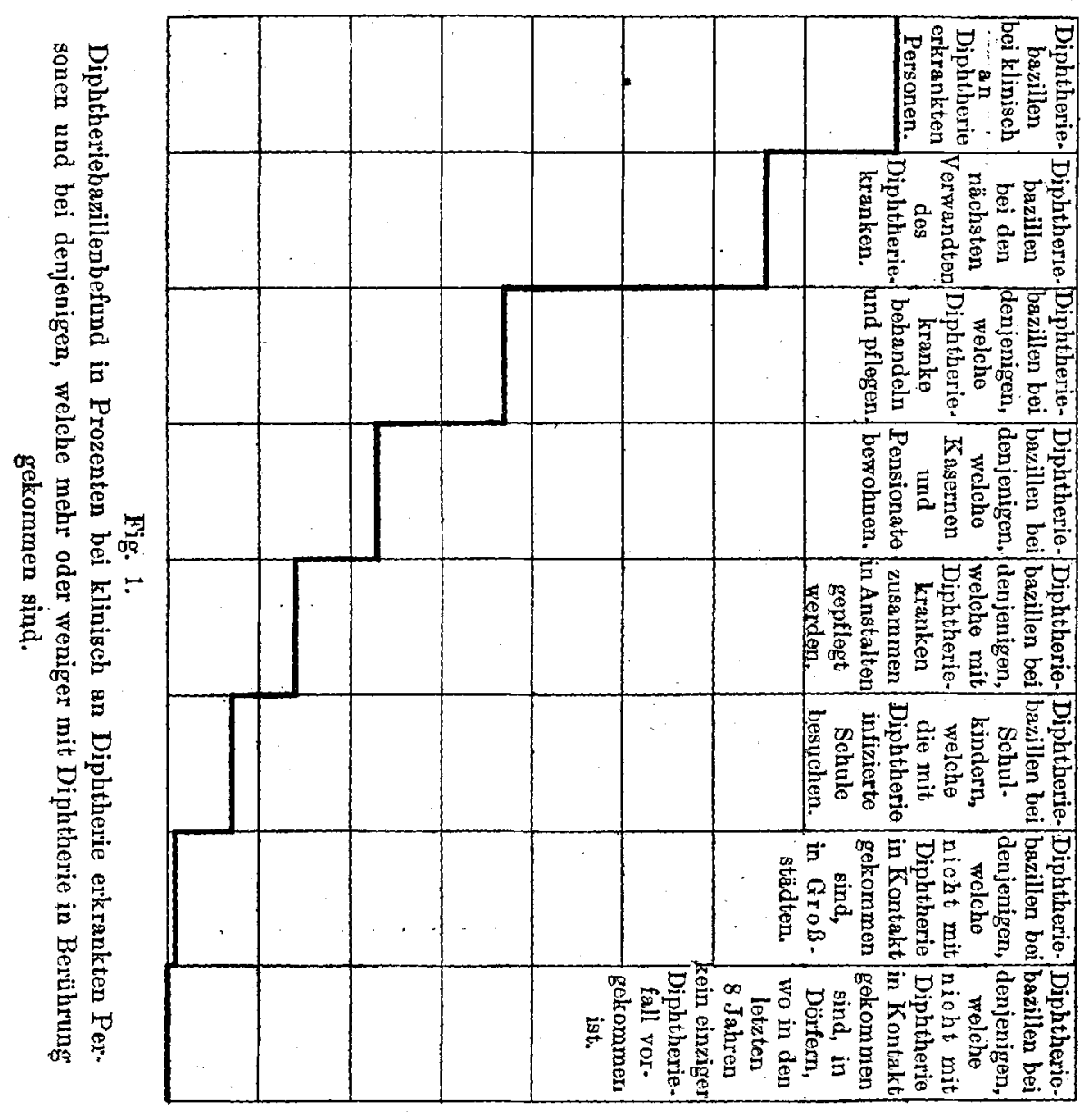

und Diphtherie zu schwächen, ist dieser Befund nur ein neuer Beweis für meine Behauptung.

Die Kurve sinkt also immer mehr herab, von 66.0 bis 0.0 Prozent, je nachdem der Kontakt mit Diphtherie weniger innig wird (Fig. 1). Es ist darin ein so großer und strenger Parallelismus zu erblicken, daß die Behauptung von v. Behring, daß die Diphtheriebazillen ubiquitär seien und ebenso wie die Pneumokokken uiberall gefunden werden könnten, auch da, wo sich die betreffende Krankheit gar nicht zeigt, absolut keinen Grund hat und durch diese Tatsachen widerlegt wird. 
Werden Diphtheriebazillen bei Gesunden gefunden, so wird man, wenn man nur gut nachforscht, immer imstande sein, den Kontakt mit Diphtherie nachzuweisen.

Es besteht ein strenger Parallelismus zwischen Diphtheriekranken und gesunden Bazillenträgern.

Keine Diphtheriebazillen ohne Diphtherie.

\section{Zur Lokalisation des klassischen Bac. Hofmanni im menschllchen Körper.}

Der typisehe Pseudodiphtheriebacillus, wie Hofmann ihn zuerst im Jahre 1887 ausführlich beschrieben hat, ist überall in der Literatur als ein Bewohner der Nasenrachenhöhle bekannt.

Von Anfang an, seit ich mich mit der balsteriologischen Untersuchung von Rachen- und Nasenhöhle, besonders von Kindern, beschäftigt habe, ist mir folgende Eigentümlichkeit stets aufgefallen: die Anhäufung des Bac. Hofmanni auf der Nasenschleimhaut. Dies war so auffallend und zeigte sich so konstant, dáB es nicht reiner Zufall sein konnte.

Wurde der Bac. Hofmanni zugleich auch im Rachenschleim gefunden, dann war die Anzahl erstens sehr viel geringer, und zweitens waren die Bazillen mit anderen Bakterien so verunreinigt, daß von einer Reinziichtung kaum die Rede sein konnte. .

Ich für meine Person habe den Eindruck bekommen, daß der Bac. Hofmanni ohne Zweifel eine sehr viel größere Affinität zur Nasenschleimhaut zeigt - und als ein echter Nasenhöhlenbewohner aufgefaßt werden muB.

Selten findet man in der Literatur Angaben, daß Rachen- und Nasenhöhle von eventuellen Keimträgern zugleich untersucht wurden. Der Gedanke, daß die Diphtherie eine primäre Rachenkrankheit ist, steht bei den Forschern so im Vordergrund, daß die Nasenuntersuchung meistens nicht in Betracht gezogen wird. Um aber eine größere Affinität eines bestimmten Mikroorganismus gegenüber Rachen- oder Nasenhöhle feststellen zu können, ist eine gleichzeitige Untersuchung dieser beiden Schleimhäute bei demselben'Individuum geboten, wie ich selbst sie auch immer vorgenommen habe. Glücklicherweise habe ich noch einige Forseher auffinden können, welche diese gleichzeitige Untersuchung auch vorgenommen haben, und zu meiner Freude stimmen die Zahlen mit den meinigen überraschend überein.

Bei den Diphtheriekontakten fand:

van Riemsdyk bei einer Schuluntersuchung Bac. Hofmanni im Rachen allein bei .......... 3. 30 Proz. 
Bac. Hofmanni in der Nase allein bei . . . . . . . 44.0 Proz. in Nasen und Rachen bei .......... 8. 8. ".

Stadler unter 464 untersuchten Kindern bei 49 Bac. Hofmanni im Rachen allein . . . . . . . . . 10.5 ", bei 186 Bac. Hofmanni in der Nase allein . . . . 40.0 ", Das Massachusetts Committee (1902) in Minnesota fand unter 1154 untersuchten Kindern Bac. Hofmanni im Rachen

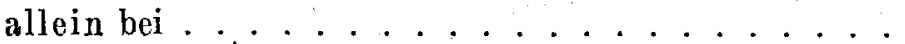
in der Nase allein bei $14 \cdot 5$, $33 \cdot 0$, :

De Simoni ohne genaue Zahlen anzugeben, sagt: „Die Pseudodiphtheriebazillen sind als gewöhnliche Kommensalen der Nasenschleimhaut aufzufassen."

Lesieur fand Bac. Hofmanni im Rachen allein bei . . . . $3 \cdot 0$ ", in der Nase allein bei ........... 4 43.0 ",

Pugh fand unter 414 untersuchten searlatinakranken Kindern Bac. Hofmanni im Rachen allein bei . . . . . . 16.0 ", in der Nase allein bei . . . . . . . . . 56.5 ",

Richardière und Tollemer von 16.Untersuchten (Krankenhauspersonal) im Rachen allein bei . . . . . . 18.6 ". in der Nase allein bei . . . . . . . . . . 62.0 ", Bei Nichtdiphtheriekontakten ist' es dasselbe.

Untersuchungen des Massachusetts Committee (1902) in Ontario unter 50 Erwachsenen Bac. Hofmanni im Rachen

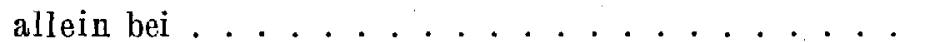
in der Nase allein bei ........................

Boston unter 892 Erwachsenen Bac. Hofmanni im Rachen allein bei .................. 5. . . . . . . in der Nase allein bei . . . . . . . . . 37.0 ",

Providence unter 927 Erwachsenen und Kindern Bac. Hofmanni im Rachen allein bei. . . . . . . . . 1. 1.0 , in der Nase allein bei . . . . . . . . . 15.0 "

Um gegenüber dem Diphtheriebacillus die größere Affinität des Hof mannschen Bacillus zur Nasenschleimhaut zu zeigen, mögen die Untersuchungen von Lambert Lack in diesem Zusammenhange genannt werden:

Bei 13 Prozent Diphtheriebazillen in der Nase, , 52 " Hofmannsche Bazillen in der Nase.

Merkwürdig ist es, daß die höchsten Zahlen (die von Pugh und Richardière und Tollemer) aus Krankenhäusern stammen; die Verhältnisse sind da natürlich andere, die Infektionsmöglichkeit größer; durch 
die permanente Rückenlage ist die Aspiration von Mikroorganismen von der Nase aus zum Rachen auch eine viel größere. Der Unterschied zwischen Rachen und Nasen ist aber auch hier verhältnismäßig derselbe.

Als Durchschnittszahlen bekommt man also hier für Erwachsene und Kinder:

\section{Bac. Hofmanni allein in der Nase bei \pm 38 Prozent} allein im Rachen bei \pm 9 "

Aus diesen Zahlen geht also deutlich hervor, daB der Bac. Hofmanni im Gegensatz zum Bac. diphtheriae eine ausgesprochene Vorliebe für die Nasenschleimhaut hesitzt.

\section{Der klassische Bacillus Hofmanni im kranken Rachen und in der kranken Nase, mit besonderer Berilcksichtigung der diphtherischen Anginae und Rhinitiden.}

Was vom bakteriologisch-diagnostischen Standpunkte aus hier am meisten interessiert, ist die Frage: ,Wie steht es mit dem Bac. Hofmanni bei der Angina diphtherica im akuten Stadium der Krankheit?" Meine eigene Erfahrung darüber geht dahin, daß ich beide Organismen nie zusammen antraf, aber mein Material ist nicht gerade groß; später, wenn die Genesung eingetreten war, und der Patient zum zweiten Male bakteriologisch untersucht wurde, fand ich fast immer den Bac. Hofmanni, und besonders in großer Anzahl in der Nase.

Wenn man in der Literatur die bakteriologische Untersuchung von Diphtheriekranken im akuten Stadium studiert, so wird man nie finden, daß die Hofmannschen Bazillen dabei auch nur irgendwelche Schwierigkeiten gemacht haben. Es ist natürlich unmöglich zu behaupten, daß die Hofmannschen Bazillen bei negativem Ausfall der Untersuchung nicht doch anwesend sein können. Zur bakteriologischen Untersuchung entnimmt man soviel wie möglich den Schleim von den Schleimhautstellen, welche am meisten durch die Krankheit betroffen sind, am liebsten dort, wo die Pseudomembranen sich vorfinden, von den anderen Stellen der Schleimhaut weiß man also nichts. Weiter untersucht man von der Loefflerplatte nur eine sehr beschränkte Zahl von Kolonien; unendlich viele bleiben ununtersucht, und endlich kann auch das langsamere Wachsen des Hof mannschen Bacillus auf Loefflerserum zur Folge haben, daß man seine Kolonien leicht übersehen kann, und die Lio efflerschen Bazillen sie ganz verdrängen.

Weil es eben mein Zweck ist, die Frage der Diphtherie-Pseudodiphtheriebazillen von allen Seiten zu betrachten, ist auch hier die Stelle, die Fälle aufzuzeichnen, in denen beide Organismen zusammen bei Diphtheriekranken im akuten Stadium angetroffen wurden. 
Zuerst die 2 Fälle Loefflers, wo er neben dem echten virulenten Diphtheriebacillus ein kleineres, plumperes Stäbchen fand, welches für Meerschweinchen nicht pathogen war.

von Hofmann-Wellenh of fand auch den falschen Diphtheriebacillus neben den echten.

Neumann bei einem Fall von Nasendiphtherie auch die zwei Organismen zusammen.

Graham-Smith, der ein äußerst zuverlässiger Untersucher ist, konnte die Hofmannschen Bazillen bei 17 Prozent seiner typischen Diphtheriefälle zugleich mit den Bac. Diphtheriae nachweisen.

Lesieur auch bei 17 Prozent.

Beck von 42 typischen Diphtheriefällen bei 19 Prozent beide Organismen zusammen.

Petri fand beide Organismen bei 3 Fällen zusammen.

Glücksmann fand auch beide Organismen zusammen bei ausgesprochener Diphtherie, er sagt: „,Die Zahl der Kolonien der Pseudodiphtheriebazillen ist in der Regel sehr gering (1 bis 5 Kolonien). Oft waren die Pseudodiphtheriebazillen erst am zweiten oder dritten Tage der Untersuchung gewachsen."

Die Frage lediglich vom praktischen Standpunkte aus betrachtend darf man ruhig sagen: Diph theriebazillen und Hofmannsche Bazillen werden im akuten Stadium der Diphtheriekrankheit selten zusammen angetroffen.

Ich brauche hier nicht weiter zu erörtern, welcher große praktische Vorteil sich hieraus ergibt insofern, als die bakteriologische Diagnose der Diphtheriekranken dadurch sehr erleichtert wird.

Auch bei anderen entziundlichen Rachen- und Nasenaffektionen wurde der Bac. Hofmanni gefunden, ohne daß auf irgendwelche Weise der Beweis erbracht ist, daß er als Ursache der Entzündung aufgefaßt werden muß. Spronck, Hewlett und Knight, Lesieur, Beck, Scheller u. a. fanden diese Organismen bei Anginae, welche sehr mild verliefen.

van Riemsdyk fand sie in großer Zahl bei zwei Fällen von Rhinitis bei Säuglingen, zusammen mit Staphylokokken und anderen Kokkenarten.

Auché und Brindel, Stein fanden den Bac. Hofmanni bei Ozaena.

Sehr interessant ist eine Untersuchung Hasslauers, der eine Anzahl gesunder und kranker Nasen von Erwachsenen der Garnison in Würzburg, also von Zusammenwohnenden, untersuchte. Er konnte feststellen, daß bei den gesunden und kranken Nasen dieselben Bazillenarten gefunden wurden, nur mit dem Unterschied, daß bei den kranken Nasen die Prozentzahl der verschiedenen normalen Nasensaprophyten stark gestiegen war, auch die des Bac. Hofmanni. 
Gesunde Nasen

$12 \cdot 0$ Prozent

$25 \cdot 3$,

$19 \cdot 9$,

$17 \cdot 2$,
Bac. pseudodiphtheriae

Staphylococcus pyogenes albus

Diplococcus pneumoniae

Streptococcus pyogenes
Kranke Nasen

37.0 Prozent

$41 \cdot 2$,

$49 \cdot 7$,

$51 \cdot 6 \quad$,

Hieraus ist wieder zu ersehen, daß Bac. Hofmanni sich wie ein echter gewöhnlicher Saprophyt verhält, welcher auch wie die anderen Saprophyten dann und wann bei verschiedenen Affektionen in den Vordergrund tretgn kann.

Utber die Pathogenität des Hofmannschen Bacillus für den Menschen ist nichts Sicheres bekannt.

Ich für meine Person glaube, daß der Bac. Hofmanni zu den gewöhnlichen Saprophyten gehört, daß es aber sehr gut möglich ist, daß er auch unter gewissen Umständen (kranke Schleimhaut, allgemeine Herabsetzung der natürlichen körperlichen Abwehrmittel, lokale Prädisposition und noch zahllose andere Faktoren) ebenso wie anderen Saprophyten imstande ist, einige krankmachende Eigenschaften zu entfalten, obgleich der direkte Beweis dafiir noch nie geliefert worden ist. Das jedenfalls wissen wir ganz entschieden, daß der Bac. Hofmanni epidemiologisch nicht die geringste Bedeutung hat. Man hat durch jene Anginae und Rhinitiden noch nie Diphtheriefälle entstehen sehen.

Neumann hat auf seiner eigenen Nasenschleimhaut eine ganze Kultur des Bac. Hofmanni verrieben, ohne irgendwelchen Erfolg.

\section{Das Vorkommen des Bac. Hofmanni bei Diphtherie- rekonvaleszenten.}

Fast immer traf ich den Bac. Hofmanni an, wenn der Diphtheriekranke im klinischen Sinne Rekonvaleszent war. Dies wurde von vielen Forsehern auch beobachtet, ich nenne hier nur: Hewlett und Knight, Westbrook, Wilson und Mc Daniel, Roux und Yersin, Roussel und Malard, Cadiot-Cathoire und Henry, Muysken.

Dieser Befund hat viele zu der Ansicht geführt, daB es damit bewiesen sei, daß der Bac. diphtheriae sich während der Rekonvaleszenz allmählich in den Bac. Hofmanni umwandelt, der toxische Bacillus in den atoxischen iibergeht und damit zugleich auch andere Eigenschaften sich ändern (Säureproduktion aus Glykose, Polkörner, Virulenz usw.).

Gorham formuliert es folgenderweise: „That the granular or barred forms are the natural forms of virulent Diphtheria bacilli, and that these forms under the influence of body fluids of persons not susceptible to the Diphtheria toxin, or who are becoming slowly immun, gradually become non-virulent, and in doing so change to the solid staining types." 
Es bedarf keiner weiteren Erörterung, daß diese Auffassungen viel zu der unendlichen Verwirrung, welche uiber dieses Problem herrschte und noch herrscht, beigetragen haben. Obwohl zuzugeben ist, daß jene Beobachtungen an eine Umwandlung denken lassen können, steht dem entgegen der Befund von Bac. Hofmanni in hohen Prozentzahlen da, wo jeder Diphtheriekontakt absolut auszuschließen ist, wo also vorher keine Diphtheriebazillen vorhanden waren. Von einer Umwandlung kann hier also unmögliçh die Rede sein, zumal im vorigen Kapitel so deutlich hervorgetreten ist, daß es nur Diphtheriebazillen gibt, wo Kontakt mit Diphtherie gwesen ist.

Ich für meine Person glaube, daß die Ursache dieses Umstandes eine ganz andere ist, nämlich daß die kranke Schleimhaut, besonders infolge der starken Hyperämie, Fibringerinnungen, Leukozytose usw. zu hoch organisierte Eiweißkörper hat, als daß der.Hofmannsehe Bacillus auf ihr gut zu wachsen vermag. Ich bin auf diesen Gedanken gekommen, weil der Bac. Hofmanni an den Nährboden nicht so große Anforderungen stellt wie der Diphtheriebacillus. Auf serum- und eiweißreichen Nährboden wächst er viel weniger schnell und üppig, es ist immer eine gewisse Retention zu beobachten in den ersten 24 Stunden, danach gleicht sich allerdings dieser Wachstumsunterschied wieder aus, und sehen dann Diphtherie- und Pseudokulturen ähnlich aus. Das Wachstum der Hofmannschen Bazillen auf gewöhnlichem Nähragar ist im Gegensatz zum Bac. diphtheriae viel üppiger und schneller, sie mehren sich selbst bei Zimmertemperatur; dann und wann ist die Kultur auch leicht pigmentiert. Ich habe den Eindruck bekommen, da $\dot{B}$ die Ernährungsphysiologie dieser zwei Bazillenarten sicher eine verschiedone ist; vielleicht, daß sie sich gegenüber differenten $\mathrm{N}$ - und C-Quellen auch anders verhalten werden.

Eine Bestätigung meiner Ansicht fand ich noch bei Beck, der unter seinen 42 typischen Diphtheriefällen, welche er bakteriologisch untersuchte, bei gleichzeitiger Benutzung von Loeffler- und Agarplatten, $8 \mathrm{mal}$ die Hofmannschen Bazillen neben den Diphtheriebazillen antraf, aber sie mur in 3 Fällen auch auf der Locfflerplatte hat finden können, die übrigen fünf nur auf. der Agarplatte. Bei diesen letzten 5 Fällen sind also die Pseudodiphtheriebazillen im Rachen nicht ganz von den echten überwachsen, und hat die Agarplatte die Anreicherung der andere Nährverhältnisse bevorzugenden Hofmannschen Bazillen ermöglicht.

Stein fand eben bei seinen 51 Ozaenafällen nur 1 mal die Hofmannschen Bazillen, während er sie 7 mal nachweisen konnte bei Personen, welche keine Ozaena hatten.

Bei gewöhnlichen Anginen sieht man doch auch, daß die eine oder 
andere Bazillenart zeitweise die Uberhand gewinnt, wie auch die Namen Streptokokken-, Staphylokokken- und Pneumokokkenanginae darauf hindeuten. Wenn die Heilung eintritt, so sehen wir auch hier die normale Flora zurückkehren; von dem Prädominieren eines bestimmten Bacillus kann dann also auch nicht mehr die Rede sein. Wie oft sehen wir nicht, daß bei Züchtung diphtherischen Materials aus dem akuten Stadium der Krankheit nur Diphtheriebazillen auf der Loefflerplatte $\mathrm{zu}$ finden sind, und daß diese die doch sehr serumliebenden Staphylokokken und Streptokokken überwuchert haben.

van Riemsdyk fand unter 21 positiven Diphtheriefällen bei 50 Prozent nur Diphtheriebazillen auf der Loefflerplatte.

Martin fand unter 69 typischen Diphtherien bei 52 nur Diphtheriebazillen auf der Platte, also bei 78 Prozent, er nannte diese denn auch „Diphthéries pures", bei den übrigen 22 Prozent waren neben den Diphtheriebazillen noch viele andere Organismen zu finden, Staphylo-, Streptokokken usw. Bei der Heilung kehren auch hier die normalen Schleimhautbewohner zurück und mit ihnen der Bac. Hofmanni.

Die Verhältnisse sind hier also den verschiedenen Kokkenarten gegenuiber beinahe dieselben, wie mit dem Hoffmannschen Bacillus (siehe Seite 67 und Fig. 4).

Muy sken sagte in seinerDissertation u. a., daß der Bac. Hofmanni immer nach der zweiten oder einer späteren Untersuchung des Patienten sich zeigte.

Wenn wir uns jetzt noch einen Augenblick an die Zeitdauer des Verschwindens des Bac. diphtheriae aus dem Rachen von Diphtheriekranken erinnern (Käpitel 6), so sehen wir, daß bei der größten Anzahl die Diphtheriebazillen ziemlich schnell verschwinden ( \pm 2 und 3 Wochen). Wir können uns also sehr gut erklären, daß bei der zweiten Untersuchung des betreffenden Patienten, welcher dann Rekonvaleszent ist, also nach \pm 2 Wochon seit die Diphtheriesymptome sich zeigten, der Bac. diphtheriae und der Bac. Hofmanni nicht häufiger zusammen gefunden werden können. Bleiben die resistenten Formen der Diphtheriebazillen in kleiner Anzahl übrig, so ist es sehr gut möglich, daß die Pseudodiphtheriebazillen und die anderen Saprophyten nunmehr die Diphtheriebazillen verdrängen.

Es ist also notwendig, bei der Untersuchung der Diphtherierekonvaleszenten möglichst viele Kolonien von der Loefflerplatte zu untersuchen, damit man die Diphtheriebazillen, wenn auch in geringer Anzahl, aufzuweisen vermag. Ich glaube, wenn die zweite baliteriologische Untersuchung des Patienten früher stattfände, die 2 Organismen auch häufiger nebeneinander gefunden würden.

Die Schleimentnahme beim Diphtherierekonvaleszenten geschieht eben 
auch unter ganz anderen Umständen. Beim Diphtheriekranken kann man sich orientieren, weil die Mukosa erkrankt ist und man soviel wie möglich von diesen erkrankten Stellen, wo sich eben die Diphtheriebazillen nesterartig anhäufen, Schleim entnimmt; man hat also hier schon eine gewisse Anreicherung. Beim Rekonvaleszenten hat man aber eine scheinbar geheilte Schleimhaut vor sich, wo man keinerlei Anhaltspunkte für die Anhäufung der Diphtheriebazillen hat. Dazu kommt noch der Umstand, daß die Kinder im letzten Fall gesund und munter sind, sich also die Rachenbehandlung öfters nicht gern gefallen lassen, die beim erkrankten Kinde in Rückenlage usw. bequemer vor sich geht. Die Chance, viel normale Saprophyten (Bac. Hofmanni) mitzuschleppen, ist also beim Rekonvaleszenten sehr viel größer. Von Zusammenvorkommen des Bac. diphtheriae und Bac. Hofmanni bei Diphtherierekonvaleszenten sind auch einige Fälle bekannt.

Cobbett isolierte bei 3 Rekonvaleszenten Bac. Hofmanni neben Bac. diphtheriae.

Graham Smith bei 6 Rekonvaleszenten Bac. Hofmanni neben Bac. diphtheriae.

Büsing bei einem gesunden Hausgenossen eines Diphtheriekranken neben einem vollvirulenten Diphtheriebacillus ein kurzes, plumpes Stäbchen, das nicht pathogen war und keine Neisserfärbung zeigte.

Im allgemeinen darf man von den Diphtherierekonvaleszenten sagen: Wird die zweite Untersuchung kurz nach der klinischen Heilung vorgenommen, so ist die Möglichkeit größer, die zwei Organismen anzutreffen; geschieht sie aber viel später, so ist die Möglichkeit gering.

Ich selber war in der Lage, die eigentümlichsten Kombinationen beider Organismen bei Diphtherierekonvaleszenten zu konstatieren. van Riemsdyk fand bei einem Schulkinde zu gleicher Zeit typische Diphtheriebazillen im Pharynx und typische Hofmannsche Bazillen in der Nase; ein anderes Mal Bac. diphtheriae und Bac. Hofmanni zugleich auf der Rachenschleimhaut. Bei den „Dauerausscheidern", also denjenigen, welche die Diphtheriebazillen lange behalten (Rekonvaleszenten und gesunde Bazillenträger), ist selbstverständlich die Möglichkeit groB, die beiden Bazillenarten zugleich anzutreffen, besonders weil die Diphtheriebazillen bei diesen Personen in der Nase haften bleiben können, und diese Schleimhaut die bevorzugte für den Bac. Hofmanni ist.

Was die bakteriologische Untersuchung des Diphtherierekonvaleszenten so unendlich viel schwerer macht als diejenige des Diphtheriekranken, ist wohl auch die längere Bebrütung. Beim Rekonvaleszenten 
dürfen eben die Loefflerplatten erst nach mindestens 24 Stunden Bebrütung bei $37 .{ }^{\circ} \mathrm{C}$ untersucht werden, weil von den Schleimhäuten entnommene Diphtheriebazillen längere Zeit zum Wachsen brauchen, was wohl von ihrer viel geringeren Anzahl und etwas herabgesetzten Vitalität abhängen wird. Neisser gibt davon folgende Zahlen: „Unter 576 Fällen von Rachenmaterial von Rekonvaleszenten, die bei der Plattenuntersuchung nach 20 Stunden glatt negativ waren, wurden 55, also 9 bis 10 Prozent, am zweiten Tage glatt positiv.“ Die "Anreicherung“, welche eben beim Diphtheriekranken sich durch langsameres Wachsen des Pseudodiphtheriebacillus und größere Anzahl der Diphtheriebazillen zeigte, fällt also beim Rekonvaleszenten gänzlich fort, da sie sich nach 24 Stunden völlig ausgleicht. Man wird also bei jeder bakteriologischen Untersuchung von Rekonvaleszenten und gesunden Bazillenträgern auf diese Faktoren bedacht sein, mindestens 24 Stunden bebrïten und viele Kolonien nachsehen müssen.

\section{Der klassische Bacillus Hofmanni bei Gesunden, welehe mit Diphtherie in Berülirung gekommen sind (Diphtheriekontakten).}

In der Monographie von Graham Smith findet man darüber große Statistiken von europäischen und amerikanischen Untersuchern. Die Zahlen gehen aber sehr auseinander, von 0.0 bis 97.0 Prozent. Auf die Ursache dieser Unterschiede hoffe ich später noch zurückzukommen. Ich erwähne diese Statistik hier aber deshalb, weil auch die Zahl der bei diesen Personen (Erwachsenen und Kindern) gefundenen Diphtheriebazillen aufgezeichnet ist. Wenn man diese Statistik studiert, dann fällt einem etwas ganz Interessantes auf, nämlich daß es absolut keinen einzigen Parallelismus gibt zwischen Bac. Hofmanni und den bei diesen Personen gefundenen Bac. diphtheriae. Auf Fig. 2 habe ich diese Zahlen, diejenigen von Graham Smith betreffs seiner eingehenden Untersuchungen von Schulen, Anstalten und Instituten in Cambridge und Colchester und noch einige von mir selbst gefundene Zahlen in Kurven dargestellt. Man sieht sofort, daß nicht die geringste Beziehung zwischen der Prozentzahl des Bac. Hofmanni und den bei diesen Personen gefundenen Diphtheriebazillen besteht.

Sehen wir jetzt, in wieviel Fällen der Bac. Hofmanni gefunden wird bei Kindern mit Diphtheriekontakt:

Graham Smith fand bei gesunden Kindern (Diphtherie-

kontakten) Bac. Hofmanni bei . . . . . . . \pm 51.4 Proz. 


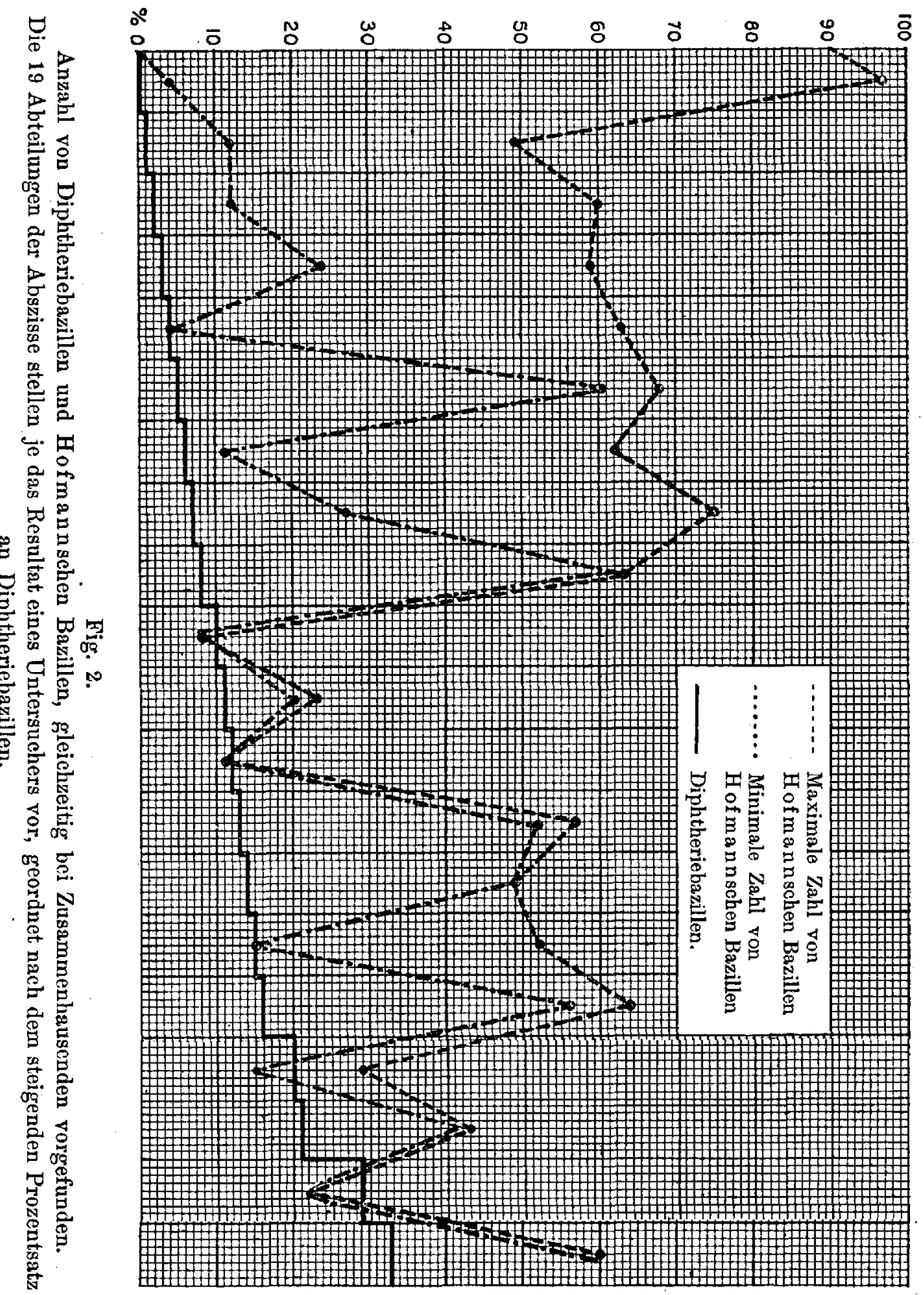

Roux und Yersin fanden in einem Pariser Kinderkrankenhause unter 45 Kindern Bac. Hofmanni bei . . . . 33.0 Proz. 
Chatin und Lesieur unter 75 untersuchten Kindern Bac. Hofmanni bei . . . . . . . . . 30.0 Proz. Cobbett unter 1724 Kindern Bac. Hofmanni bei . . . 39.0 " Béck fand unter 66 Kindern Bac. Hofmanni bei . . . 33.0 ", Glücksmann fand in einem Kinderkrankenhaus unter den 39 Kindern, die alle ganz gesunde Nasen und Rachen hatten, Bac. Hofmanni bei . . . . . . . . . . . . . .

Steenmeyer in der Chirurgischen Klinik des Kinderkrankenhauses in Rotterdam Bac. Hofmanni bei . . . . . 75.0 ,

Stokvis und van Riemsdyk in Amsterdam unter gesunden Kindern, welche mehr oder weniger mit Diphtherie in Kontakt gekommen waren, Bac. Hofmanni bei ..... $72 \cdot 0$,

Durchschnittlich unter Kindern mit Diphtheriekontakt Bac. Hofmanni bei

Bac. Hofmanni bei Erwachsenen mit Diphtheriekontakt: Mark und Pollak unter 98 Personen (bosnische Pilger und Soldaten) Bac. Hofmanni bei . . . . . . . . 24.0 Proz.

Golowkoff unter 115 Kadetten des II. Kadettenkorps in Petersburg Bac. Hofmanni bei . . . . . . . . 12.0 "

Cathoire unter 450 Militärs eines Bataillons des II. Infanterieregiments in Castelsarrazin Bac. Hofmanni bei . . . 15.5 "

Hasslauer unter 82 gesunden Erwachsenen (Militärs der Garnison Würzburg) Bac. Hofmanni bei . . . . . . 12.0 "

Graham Smith unter 268 gesunden Erwachsenen Bac. Hofmanni bei .............. . . 19.0 ",

Fibiger unter 135 gesunden Erwachsenen (8 Pflegerinnen und Krankenhauspersonal) Bac. Hofmanni bei. . . . . 11.0 ",

Durchschnittlich Bac. Hofmanni bei Erwachsenen mit Diph-

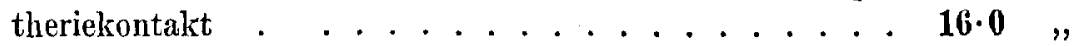

Aus diesen Durchschnittsprozentzahlen geht also deutlich hervor, daß unter den Diphtheriekontakten. die. Zahl des Bac. Hofmanni bei den Kindern (48.0 Prozent) eine sehr viel höhere ist als bei den Erwachsenen (16.0 Prozent). Auf diese Differenz hoffe ich später noch kurz zurückzukommen. Die Prozentzahlen, welche in dieser Hinsicht die Kasernen (Soldaten) geben, sind viel niedrigere: als diejenigen bei den Kindern der Volksschule (48 Prozent). Bei Diphtherie verhält es sich gerade umgekehrt (Volkschulkinder 7 Prozent, Kasernenbewohner 23 Prozent). 


\section{Der klassische Bac. Hofmanni bei Gesunden, welche nicht mit Diphtherie in Beriihrung gekommen sind (nicht Diphtheriekontakte).}

Kinder ohne Diphtheriekontakt:

Roux und Yersin sind die ersten gewesen, welche im Jahre 1890 eine Anzahl Kinder in einem Orte untersuchten (Seedorf Caën), wo in den letzten Jahren kein einziger Diphtheriefall vorgekommen war. Sie unternahmen diesen Versuch, um zu sehen, ob diese Organismen auch da gefunden würden, wo keine Diphtherie vorkam; sie fanden Bac. Hofmanni bei.

$44 \cdot 0$ Proz.

Lesieur fand unter denjenigen ,à l'abri de tout Contact"

Bac. Hofmanni bei . . . . . . . . . . . 31.5 Proz.

Graham Smith unter 100 Schulkindern Bac. Hofmanni bei Cobbett unter 90 Knaben einer Zuchtschule, wo in mehreren Jahren kein einziger Diphtheriefall vorgekommen war, Bac.

Hofmanni bei . . . . . . . . . . . . . . . . . . . .

wo in den den letzten 8 Jahren kein einziger Diphtheriefall vorgekommen war, Bac. Hofmanni bei . . . . . . .

Steenmeyer in Schelluinen bei Gorichem, wo in den letzten

10 Jahren kein einziger Diphtheriefall oder verdächtige Angina vorgekommen war, unter den Schulkindern Bac. Hofmanni bei ........... . . 50.0 ",

Stokvis und van Riemsdyk in Dörfern auf der Veluwe und Limburg, wo sich in den letzten 10 Jahren kein einziger Diphtheriefall unter den Schulkindern gezeigt hatte, Bac. Hofmanni bei . . . . . . . . . . 50.0 ", Durchschnittlich Bac. Hofmanni unter Kindern ohne Diphtheriekontakt ............ Erwachsene ohne Diphtheriekontakt:

Park und Beebe fanden unter 257 untersuchten Erwachsenen Bac. Hofmanni bei . . . . . . . . . . . 10.5 Proz.

Leider habe ich für diese Kategorie nur diese eine Prozentzahl finden können, weshalb hier keine Durchschnittszahl aufzumachen ist; sehr wahrscheinlich wird sie aber derselben Zahl entsprechen wie bei den Kontakten.

Beim Vergleich dieser Durchschnittsprozentzahlen fällt es sogleich auf, daß das Vorkommen oder Nichtvorkommen von Bac. 
diphtheriae in der Umgebung durchaus keinen Einfluß auf die Prozentzahl des Bac. Hofmanni ausübt.

Wenn es nun wirklich so wäre, daß der Bac. Hofmanni ein avirulentatoxisch gewordenes Diphtheriestäbchen sei, so hätte man meines Erachtens nur zwei Möglichkeiten:

a) Entweder die Prozentzahl des Bac. Hofmanni wird da, wo viele Diphtheriefälle vorgekommen sind, bei den gesunden Diphtheriekontakten viel niedriger sein müssen, weil viele von diesen avirulenten Organismen (unter dem Einflub zahlloser unbekannter Faktoren) wieder virulent und also Diphtheriebazillen werden;

b) oder die Prozentzahl des Bac. Hofmanni wird bei solchen Personen stark erhöht sein, weil durch die vielen Diphtheriefälle auch wieder viele avirulente Bac. diphtheriae entstehen werden.

Jedenfalls würde man irgendwelche Beeinflussung erwarten müssen.

Das Vorkommen von Bac. Hofmanni da, wo kein einziger Fall von Diphtherie oder verdächtiger Angina sich seit mehreren Jahren gezeigt hat, bleibt, wenn man es als ein avirulent gewordenes Diphtheriestäbchen ansieht, unerklärlich. Das nie wieder pathogen (virulent-toxisch)-Werden dieser Keime ist meines Erachtens auch ein Beweis dafür, daß es eine andere Bazillenart ist, denn bei fast allen pathogenen Organismen sind Virulenz und Avirulenz mehr oder weniger labile Eigenschaften, und es ist nicht anzunehmen, daß gerade der Bac. diphtheriae sich in dieser Hinsicht so beständig verhalten sollte. Ich selbst habe gerade bei Bac. diphtheriae die Virulenz und Avirulenz als eine sehr schwankende Eigenschaft gefunden.

Es wäre undenkbar, daß ein avirulent gewordenes pathogenes Stäbchen in einer Umgebung, wo es sicherlich viele kränkliche, schwache Individuen mit sehr prädisponierten Schleimhäuten gibt, in so vielen Jahren keinen geeigneten Nährboden zur Wiederentfaltung seiner krankmachenden Eigenschaften finden sollte, wo auf künstliche Weise (Trump, Bardach, Schmitz) und spontan (van Riemsdyk) bei virulenten Kulturen, welche die Virulenz völlig eingebüßt hatten und sie nach kurzer Zeit wieder spontan zurückbekamen, die Virulenzsteigerung wohl gelungen ist. Während wir für den Diphtheriebazillus eine so ausgesprochene herabsinkende Kurve haben, je nachdem der Kontalkt mit Diphtherie weniger innig wird, zeigt sich bei den Bac. Hofmanni nicht der geringste Zusammenhang und keinerlei Beeinflussung durch Berührung oder Nichtberührung mit Diphtherie. Die Untersuchungen von Roux und Yersin sind namentlich sehr beweiskräftig 
im diphtheriefreien Seedorf Bac. Hofmanni bei . . . . 44.0 Proz. im Krankenhaus zu Paris . . . . . . . . . . 33.0 ",

Auf Fig. 3 habe ich einige Untersuchungen von Forschern dargestellt, welche teils in der Nāhe von Diphtherie untersuchten, teils

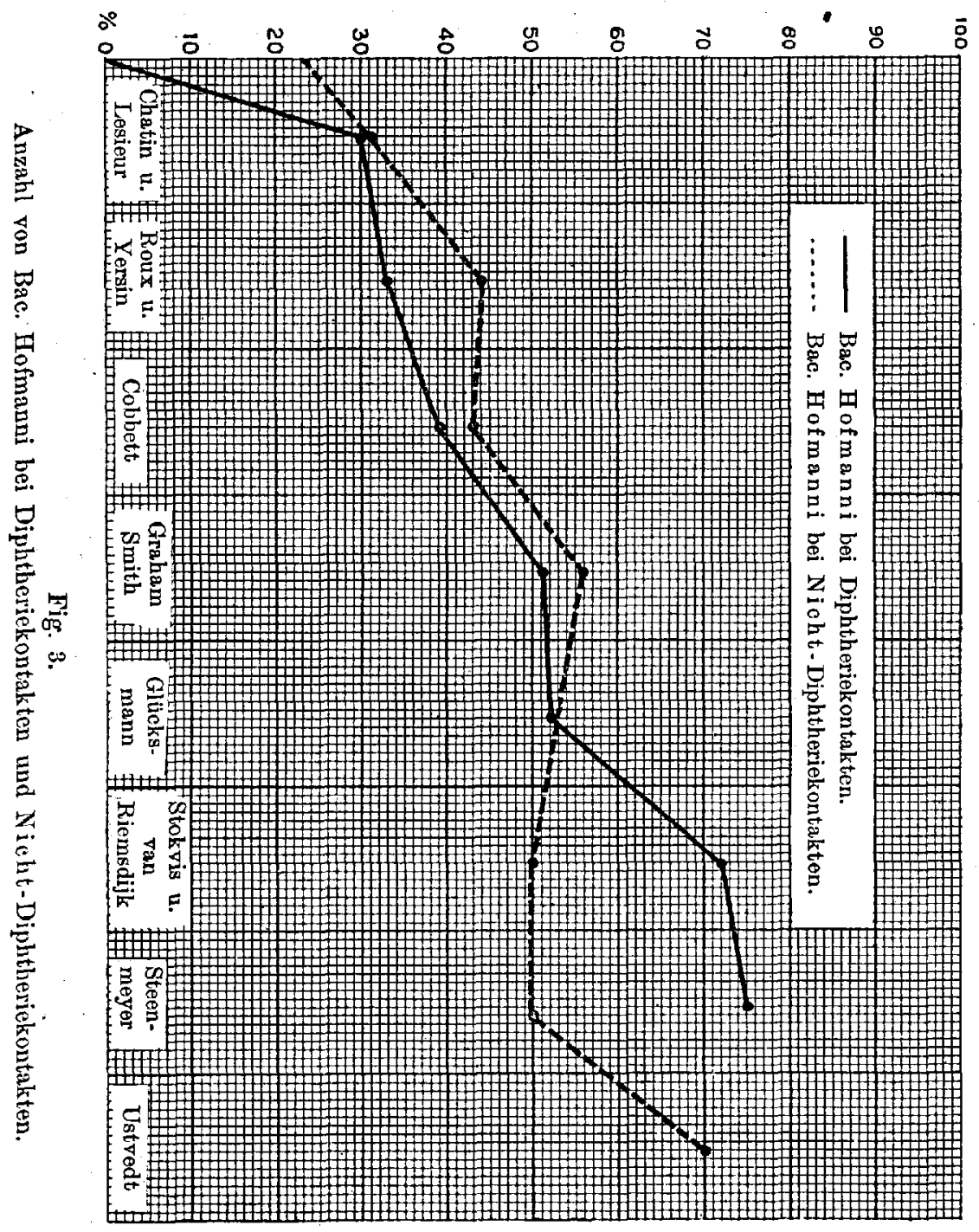

da, wo kein Kontakt mit Diphtherie nachgewiesen werden konnte. Die Kurven lassen aufs deutlichste ersehen, daB von einem konstanten Unterschiede absolut keine Rede ist. 


\section{Einfluß der sozialen Lage und Reinlichkeit auf die Ver- breitung des Bac. Hofmanni auf Nasen- und Rachenschleimhaut.}

Graham Smith macht uns, als Resultat seiner umfangreichen Untersuchungen in Cambridge und Colchester, auf einige sehr interessante Tatsachen aufmerksam.

1. Daß keinerlei Beziehung besteht zwischen den Bac. Hofmanni und den bei diesen Personen gefundenen Bac. diphtheriae.

2. Daß die Prozentzahl des Bac. Hofmanni bei den Kindern eine viel höhere ist, als bei den Erwachsenen.

3. Daß die Prozentzahl bei ärmeren Kindern wieder eine viel höhere ist, als bei den Kindern aus besseren Ständen.

- Er gibt davon folgende Zahlen:

Erwachsene aus den unteren Volksschichten ohne Diphtheriekontakt Bac. Hofmanni bei. . . . . . . 20.6 Proz.

Erwachsene aus besseren Ständen, Studenten ohne Diphtheriekontakt, Bac. Hofmanni bei . . . . . . 9.0 ",

Kinder aus den unteren Volksschichten ohne Diphtheriekontakt Bac. Hofmanni bei . . . . . . . 55.0 ",

Kinder aus besseren Ständen, ohne Diphtheriekontakt Bac. Hofmanni bei . . . . . . . . . . 8.0 "

Bei den Diphtheriekontakten ist es genau dasselbe.

Roux und Yersin und Cobbett fanden das gleiche. Dies läßt sich auch leicht erklären. Ärmere Kinder in der Schule haben meistens die schlechte Gewohnheit, ihre Bleistifte, Griffel usw. abzubeißen, welche sie dann wieder einander leihen. Schiefertafeln werden oft mit der Zunge gereinigt, gehen auch wieder von Kind zu Kind, Taschentücher sind meistens gemeinsames Gut, genügende Faktoren, um diesen anspruchslosen Saprophyten, der, wenn er bei den Kindern sich findet, meistens in sehr großer Zahl anwesend ist, von einem Kinde zum andern zu überpflanzen. Die Klassen der Volksschulen sind dabei meistens so groß, daß die Aufsicht nicht immer genügend streng sein kann.

Bei den Erwachsenen, welche die schlechten Gewohnheiten viel weniger zeigen, ist die Prozentzahl von Bac. Hofmanni naturgemäß auch eine viel niedrigere, 9.0 Prozent bei denjenigen in sehr guter sozialer Lage, 20.6 Prozent bei denjenigen aus dem Volksstande. Die Zahlen von Mark 
und Pollack und Graham Smith (siehe Bac. Hofmanni bei Erwachsenen mit Diphtheriekontakt, Seite 73), welche die höchsten sind, sind in diesem Zusammenhange interessant. Sie stammen eben auch von Personen aus sehr armen Klassen.

Einen Augenblick möchte ich noch bei den Prozentzahlen aus Holland verweilen, weil sie ebenfalls in diesem Verbande interessant sind. Die Zahlen von Steenmeyer und Stokvis und van Riemsdyk stimmen überraschend überein:

In den Großstädten (Amsterdam und Rotterdam) . . . 73.0 Proz. In den diphtheriefreien Dörfern . . . . . . . 50.0 ,

Bei beiden ist die Prozentzahl in den Großstädten eine höhere als in den Dörfern; die untersuchten Kinder gehören aber alle den unteren Volksklassen an. In den sozialen Verhältnissen kann also die Ursache des Unterschiedes nicht liegen. Ich für meine Person glaube, daß sie darauf beruht, daß der Kontakt zwischen den Kindern in einer Großstadt ein viel größerer ist, als in einem Dorfe. Erstens stehen in einem Dorfe die Häuser viel weiter auseinander; öfters stehen die Bauernhäuser sogar ganz isoliert; dann ist die Entfernung zwischen Schule und Haus oft eine so große, daß die Kinder nach der Schule nicht so lange auf der Straße miteinander spielen können, wie es in einer Großstadt fast immer stattfindet.

In den Großstädten, wo meistens bakteriologische Untersuchungen planmäßig vorgenommen werden, weil das Sanitätswesen durch die Gesundheitsämter viel besser organisiert ist als auf dem Lande, hat man aber dessenungeachtet aus obigen Gründen leider am meisten mit diesen banalen Saprophyten zu kämpfen.

Bei einer Reihe von Untersuchungen an Säuglingen fand ich, daß Bac. Hofmanni nicht nur in der Nase anwesend waren, sondern auch in ziemlich großer Zahl im Rachen, hier aber meistens nicht in Reinkultur. Von 21 Untersuchungen an Säuglingen:

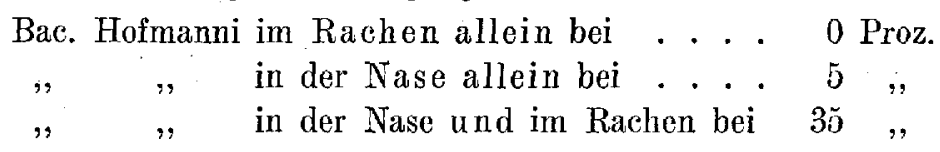

Dies war zu auffallend, als daß es reiner Zufall sein konnte, weil ich es bei größeren Kindern so selten sah. Die Ursache dieses Befundes muß nach meiner Meinung folgenden Umständen zugeschrieben werden:

1. Der permanenten Rückenlage des Säuglings.

2. Dem vielen Aspirieren und Saugen. 
3. Dem kleinen Abstande zwischen Nasen- und Rachenhöhle, welcher bei größeren Kindern mit dem Herauswachsen der Nase zunimmt (kümmerliche Entwickelung der Conchae, Vibrissae usw. sind auch wohl von Einfluß).

4. Der Schwierigkeit, Nase und Mund bei Säuglingen rein zu halten; alles Faktoren, welche es ermöglichen, daß ein derartiges Kind sich selbst weiter infiziert.

Es versteht sich aus all dem Gesagten auch leicht, warum die Zahlen der Untersucher hinsichtlich des Vorkommens des Bac. Hofmanni so weit auseinandergehen; sie haben ihr Untersuchungsmaterial, ohne darauf zu achten, aus allen Bevölkerungsschichten gesammelt, bald Erwachsene, bald Kinder, bald Rachen und bald Nasen zu ihren Untersuchungen benutzt. Der primäre Sitz des Bac. Hofmanni ist die Nase, wird der Rachen infiziert, so ist es fast immer eine durch mechanische oder andere Einflüsse (Aspiration, Unsauberkeit) bewirkte Infektion von der Nase aus (Kapitel 9). Wie oft sieht man nicht, auch bei guterzogenen Kindern, daß sie so eingenommen sind durch ihr Spiel, daß sie es langweilig finden ihre Nase zu putzen, und wenn das Nasensekret abläuft, es ganz ruhig mit der Zunge ablecken. Ist es denn zu wundern, daß Bac. Hofmanni auch in dem Rachen sich öfters zeigt?

Bei Säuglingen findet sich also in Nase und Rachen öfters der Bac. Hofmanni; bei größeren Kindern beschränkt er sich, infolge der Entwicklung der Nase, der aufrechten Körperhaltung und größerer Reinlichkeit, überwiegend auf die. Nasenschleimhaut, und bei Erwachsenen ist er wegen vermehrter Reinlichkeit in viel geringerer Anzahl vorhanden als bei den Kindern, hier auch überwiegend auf der Nasenschleimhaut. Dazu kommen die durch die soziale Lage bedingten Unterschiede. Reinlichkeit hat eben großen Einfluß auf Anzahl und Sitz des Bacillus Hofmanni, so daß er bei Personen aus ärmeren Klassen in viel höherer Prozentzahl anwesend ist, als bei denjenigen in besserer sozialer Lage. All das Gesagte resümierend, seien nachstehend die Ergebnisse für beide Bazillenarten einander gegenübergestellt:

Bacillus diphtheriae.

1. Die Schleimhaut, zu der der Bac.- diphtheriae die größte Affinität hat, ist die Rachenschleimhaut (Kapitel 3, 4 bis 5).
Bacillus Hofmanni.

1. Die Schleimhaut, zu der der Bac. Hofmanni die größte Affinität hat, ist die Nasenschleimhaut (Kapitel 9). 
2. Man hat den Bac: diphtheriae in erster Stelle zu suchen bei der Angina diphtherica und der Rhinitis diphtherica (Kapitel 4 und 5).

3. In zweiter Stelle hat man Bac. diphtheriae bei denjenigen zu suchen, welche mit Diphtherie in Berührung gekommen sind; er findet sich in desto niedrigerer Prozentzahl, je weniger innig der Kontakt mit Diphtherie (von 66.0 bis 0.5 Prozent) ist (Kapitel 7 und Fig. 1 ).

4. Bac. diphtheriao wird nicht gefunden da, wo keine Berührung mit Diphtherie stattgefunden hat (0.0 Prozent) (Kapitel 8).

5. Während der Rekonvaleszenz verschwindet Bacillus diphtheriae schnell von den Schleimhäuten (Kapitel 6).

6. Bac. diphtheriae wird unter den gesunden Diphtheriekontakten am wenigsten häufig beim Kinde der Volksschule gefunden (7.0 Prozent) (Kapitel 7).

7. Für die Verbreitung des diphtherischen Virus von einem Individuum zum anderen ist ein inniger Kontakt notwendig (Kapitel 7 und Seite 81).

8. Die Prozentzahl des Bac. diphtheriae für die Erwachsenen und Kinder wird nur beeinflußt durch die Intensität des Kontaktes mit dem Diphtheriekranken (Kapitel 7).
2. Bac. Hofmanni wird in den Pseudomembranen bei der Angina diphtherica und der Rhinitis diphtherica nur selten angetroffen (Kapitel 10).

3. Bac. Hofmanni wird in gleicher Prozentzahl angetroffen, da wo Kontakt und wo kein Kontakt mit Diphtherie stattgefunden hatte (48 und 49 Prozent) (Kapitel 12 bis 13 ).

4. Bac. Hofmanni wird bis $\mathrm{zu}$ 49.0 Prozent angetroffen da, wo keine Berührung mit Diphtherie stattgefunden hat (Kapitel 13).

5. Bac. Hofmanni erscheint in der Diphtherierekonvaleszenz auf den Schleimhäuten wieder (Kap. 11).

6. Bac. Hofmanni wird beim Kinde der Volksschule am häufigsten gefunden (49 Proz.) Kap. 12).

7. Für die Verbreitung des Bac. Hofmanni von einem Individuum zum anderen braucht der Kontakt nicht so innig zu sein (Seite 81 und Kapitel 14).

8. Erwachsene, sowohl nach Diphtheriekontakt wie ohne Diphtheriekontakt, zeigen den Bac. Hofmanni in einer viel niedrigeren Prozentzahl als die Kinder (16 und 49 Prozent) (Kapitel 12 bis 13). 
9. Für die Verbreitung der Diphtherie spielen die "Gegenstände" eine untergeordnete Rolle. Innige Berührung mit dem Kranken und Bazillenträger (Küsse, Tröpfcheninfektion beim Sprechen, Taschentiicher, körperliche Pflege, Zusammenschlafen usw.) ist der Weg, wodurch hier die Infektion zustande lrommt (Kapitel 7 und Seite 81 ).

10. Der Klebs-Loefflersche Diphtheriebacillus ist ein echter Parasit und gehört zu der obligaten Parasitengruppe (Kap. 3 u. 6).
9. Für die Verbreitung des Bac. Hofmanni spielen wahrscheinlich die „Gegenstände ${ }^{\text {‘ }}$ die Hauptrolle (Kapitel 12, 13, 14 und Seite 81).

Durch meine Ausführungen ist wohl genügend bewiesen, daß die „dualistische" Anschaung die richtige ist, daß Bac. diphtheriae und Bac. Hofmanni nicht nur aus rein bakteriologisch-serologischen Gründen, sondern auch aus biologisch-epidemiologischen Gründen als zwei verschiedene Bazillenarten betrachtet werden müssen, daß Bac. diph theriae ein echter Parasit - Bac. Hofmanni ein echter hajmloser Saprophyt ist.

Es ist eben eine bedauernswerte Koinzidenz, daß die Diphtherie eine echte Kinderkrankheit ist, und der Bac. Hofmanni ebenfalls am häufigsten bei Kindern vorkommt, Auf Fig. 4 habe ich versucht eine übersichtliche Kurve zusammenzustellen der verschiedenen Durchschnittsprozentzahlen der Diphtherie- und Hofmannschen Bazillen bei Diphtheriekranken, bei den gesamten Diphtheriekontakten (Erwachsene und Kinder) und bei den Nicht-Diphtheriekontakten (diphtheriefreie Gegenden, Erwachsene und Kinder), nachdem ich die mittlere Zahl der verschiedenen Gruppen (Durchschnittsprozentzahlen) berechnete.

Daß die epidemiologischen Verhältnisse bei Bac. diphtheriae und Bac. Hofmanni verschiedene sind, ist wohl im vorstehenden deutlich zutage getreten; die Kurve von den Hofmannschen Bazillen bleibt, außer der Diphtheriekrankheit, also bei gesunden mit oder ohne Diphtheriekontakt, auf gleicher Höhe. Während für die Verbreitung des diphtherischen Virus ein inniger Kontakt nötig ist (Küsse, Husten, Pflege, Tropfeninfektion beim Sprechen, Taschentücher, Zusammenschlafen usw.), spielen sehr wahrscheinlich beim Bac. Hofmanni die "Gegenstände". eine große Rolle bei der Verbreitung, was auch erklärlich ist, da der Bac. Hofmanni 
Mittlere Zahlen der Diphtherie- und Hofmannschen Bazillen bei Diphtheriekranken, bei den gesamten Diphtheriekontakten und bei den nicht Diphtheriekontakten.

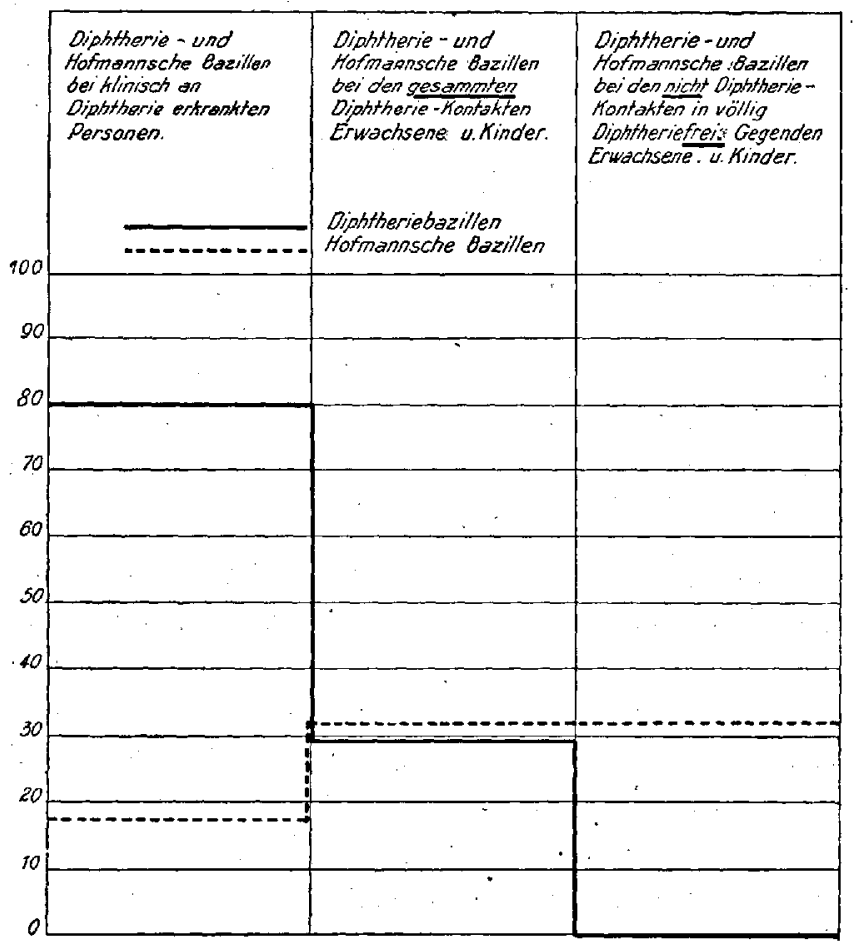

Fig. 4.

viel leichter ein saprophytisches Leben führen kann; als der Bac. diphtheriae. In Utbereinstimmung hiermit wird der Bac. Hofmanni am häufigsten bei den Volksschulkindern gefunden, wo eben die Gegenstände soviel zirkulieren.

Im vorstehenden ist bereits nebenbei die Beantwortung vieler mehr rein bakteriologischer Fragen berührt, namentlich auch der wichtige Punkt, wie die bakteriologischen Verhältnisse sich beim Diphtheriekranken, beim Diphtherierekonvaleszenten und beim gesunden Bazillenträger gestalten. Ohne hier in die technisch-bakteriologischen Fragen tiefer einzudringen, möchte ich doch folgendes besonders besprechen: „Was hat man beim Diphtheriekranken, Rekonvaleszenten und gesunden Bazillenträger mit spezieller Berücksichtigung des. Bac. Hofmanni vom bakteriologischen Standpunkt aus zu erwarten?" 
Bei der bakteriologischen Untersuchung der Diphtherie werden zwei Sachen vom Bakteriologen gefordert:

1. Die Untersuchung des Diphtheriekranken im akuten Stadium der Krankheit, also die Untersuchung der erkrankten Schleimhaut.

2. Die Untersuchung des Diphtherierekonvaleszenten und gesunden Bazillenträgers, also die Untersuchung der heilenden und gesunden Schl eimhaut.

Wir wissen alle, daß die Schleimhautflora schon unter normalen Bedingungen kleineren und größeren Schwankungen unterworfen ist, daß aber bei der erkrankten Schleimhaut das Gleichgewicht sich so absolut andert, daß man von einer völligen Umwandlung der Flora reden darf. Die Verhältnisse sind also bei der kranken und der gesunđen Schleimhaut ganz verschiedene, und das übt natürlich einen direkten Einfluß aus auf die bakteriologische Untersuchung selbst. Es fragt sich nun: Sind die Schwierigkeiten der Untersuchung in beiden Fällen gleich groß? Schon aus dem Gesagten geht hervor, daß die Verhältnisse beim Diphtheriekranken viel günstigere sind, als beim Rekonvaleszenten und gesunden Bazillenträger, nicht nur was die Pseudodiphtheriebazillen anbelangt, sondern auch die Züchtung des Diphtheriebacillus selbst. Im übrigen verweise ich auf die nachstehende Gegenüberstellung:

Diphtheriekranke im akuten Stadium der Krankheit.

1. Die Diphtheriebazillen häufen sich an den erkrankten Partien der Schleimhaut an und vermehren sich an diesen Stellen (Seite 8).

2. Von diesen erkrankten Stellen wird mit Vorliebe Schleim zur bakteriologischen Untersuchung entnommen. Man hat also hier eine gewisse Orientierung zur Schleimentnahme, wodurch schon eine Anreicherung der Diphtheriebazillen stattfindet (Seite 40, 70).
Diph therierekonvaleszenten und gesunde Bazillenträger.

1. Bei $\pm 2 / 3$ der Fälle verschwinden die Diphtheriebazillen schon nach 2 bis 3 Wochen von der Schleimhaut. Bei dem übrigen $1 / 3$ der Fälle verbleiben die Diphtheriebazillen länger auf den Schleimhäuten (Kapitel 6).

2. Für die Schleimentnahme hat man auf der anscheinend geheilten und gesunden Mukosa keinen einzigen Anhaltspunkt. Das Mitschleppen von vielen Saprophyten, auch Bac. Hofmanni, ist davon die direkte Folge (Seite 70). 
3. Bei den meisten Diphtheriefällen haben die Diphtheriebazillen die anderen Keime überwuchert, werden also nicht gehemmt und auf der Loefflerplatte noch weiter angereichert (Kapitel 10 und Seite 69).

4. Wenn keine direkten Indikationen dafür gegeben sind, braucht die Nasenuntersuchung hier meistens nicht stattzufinden (Kapitel 4,5 ).

5. Bac. Hofmanni wird selten auf den an Diphtherie erkrankten Schleimhautstellen (Pseudomembranen) gefunden (Kapitel 10).

6. Weil die Diphtheriebazillen meistens in großer Zahl anwesend sind, wachsen sie schnell und üppig auf der Loefflerplatte, so daß man die Hofmannschen Bazillen, wenn diese doch vorhanden sind, infolge ihres langsameren Wachsens auf eiweißreichen Nährböden viel eher ausschließen kann (Seite 68, 69).
3. Die Möglichkeit, daß die Diphtheriebazillen, zumaI sie hier meistens nicht in so großer Zahl anwesend sind, beim Eintreten der normalen Verhältnisse durch die Saprophyten überwuchert werden, ist hier grob (Seite 69).

4. Durch die Möglichkeit des Verbleibens der Diphtheriebazillen auf der Nasenschleimhant darf gerade die Nasenuntersuchung (die Prädilektionsstelle des Bac. Hofmanni) hier nicht unterlassen werden (Seite 52,60).

5. Bac. Hofmanni ist ein normaler Bewohner der gesunden Rachen-Nasenschleimhaut und zeigt sich oft in erheblichen Quantitäten (Kapitel 9, 12, 13).

6. Weil die Diphtheriebazillen hier in kleiner Anzahl anwesend sein können, ihre Wachstumenergie oft abgenommen hat, und die Saprophyten durch ihre große Anzahl und Stoffwechselprodukte hemmend wirken können, muß den Diphtheriebazillen Zeit gelassen werden, sich $\mathrm{zu}$ entwickeln. Eine längere $\mathrm{Be}$ brütung (mindestens 24 Stunden) ist hier also angezeigt. Der Wachstumsunterschied, der nach \pm 12 bis 20 Stunden zwischen beiden Bazillenarten noch besteht, wird durch die längere Bebrütung aufgehoben; die Saprophyten und auch der Bac. Hofmanni können dann aber auch viel üppiger wachsen, wodurch die Untersuchung wieder sehr erschwert wird, und die Untersuchung von einer großen Anzahl Kolonien geboten ist (Seite 69 u. 71). 
Џ̇ber die Frage der Diphtherie- und Pseudodiphtheriebazillen. 85

Ich will, wie gesagt, an dieser Stelle nicht die ganze bakteriologische Technik der Diphtherieuntersuchung und die kritische Beurteilung der verschiedenen differentielldiagnostischen Methoden behandeln; ich verweise in dieser Hinsicht auf zwei meiner Arbeiten, in denen ich diese Fragen ausführlich erörtert habe.

Jedenfalls steht fest, daß die bakteriologische Untersuchung des Diphtherierekonvaleszenten in jeder Hinsicht eine viel schwierigere und mühsamere ist als die des Diphtheriekranken und nur den Händen von sehr Geübten anvertraut werden soll.

Die bakteriologische Diagnostik eröffnet zur erfolgreichen Diphtheriebekämpfung den einzig sicheren Weg, und der Bakteriologe hat es daher zum großen Teil in der Hand, ob die so gefährliche Kinderkrankheit weiterverbreitet wird. Es ist aber auch andererseits notwendig, vor unnötiger Isolierung von Personen, welche keinerlei epidemiologische Gefahr bieten, zu warnen. Unbedingt notwendig ist es darum, die bakieriologische Untersuchung von Diphtherierekonvaleszenten und Gesunden mit größter Sorgfalt und Genauigkeit vorzunehmen und die differentielle Diagnostik zu verwerten, damit der Bac. diphtheriae vom Bac. Hofmanni geschieden wird, und nur echte Diphtheriebazillenträger isoliert werden. 


\section{Literaturverzeichnis.}

Aaser, Deuische med. Wochenschr. 1895. Nr. 22.

Abbott, Med. News. 1893. 15. Zitiert von Graham Smith.

Derselbe, Centralbl. für Bakt. Abt. I. Ref. 1892. Bd. XII.

Arkwright, Joum. of Hygiene. 1908.

Anché und Brindel, Semaine Méd. 1897. Zitiert von Lesieur.

von Behring, Bibl, von Coler. Berlin 1901. II. Zitiert von Lesieur.

Beck, Diese Zeitschr. 1890. Bd. VIII.

Bauer, Hygienische Rundschau. 1907.

Baginsky, Die Serumtherapie der Diphtherie. Berlin 1895.

Derselbe, Diphtherie und diphtherisoher Croup. Wien 1898.

Bardach, Annales de l'Institut Pasteur. 1895.

Büsing, Diese Zeitschr.' 1907. 'Bd. LVII.

Ballin, Centralbl. für Bakt. 1904. Ref. Bd, XXXV.

Burnett, Brit. med. Journ. 1900. II. Zitiert von Graham Smith.

Blochman; Ref. Ned. Tydschr. v. Geneeskunde. 1910. II B.

Bonhoff, Diese Zeitschrift. 1910. Bd. LXVII.

Cohn, Mitt. aus den Grenzgebieten der Medizin und Chirurgie. 1904. Bd. XIII.

Conradi, Hygienische Rundschau. 1914.

Cobbett, Journ of Hygiene. 1901. I. Zitiert von Graham Smith.

Derselbe, Journ. Royal Sanit. Inst. 1904. XXV. Zitiert von Graham Smith.

Concetti, Ref. Centralbl. für Bakl. 1892. Bd. XIT. Smith.

Crowley und Eurich, Brit. med. Journ. 1904. I. Zitiert von Graham

Chatin und Lesieur, Revue d'Hygiène. 1900. XXII.

Cadiot-Cathoire und Henry, Revue d'Hygiène. 1911. I 33.

Cathoire, Revue d'Hygiène. 1912. II. Smith.

Dowson, Report of Med. off. of Health. Bristol 1893. Zitiert von Graham

von Drigalsky, Centralbl. für Bakt. 1909. Ref. Bd. XLIV.

Diphtheriestation in Breslau, zitiert von Kober.

Denny, Boston Med. and Surg. Journ, 1900. CXLIII. Zitiert von Graham Smith.

Escherich, Centralbl. für Bakt. 1890. Bd. VII.

Fraenkel, Berliner klin. Wochenschr. 1893.

Derselbe, Hygienische Rundschau. 1896.

Fibiger, Centralbl. für Bakt. 1898. Ref. Bd. XXIII.

Derselbe, Baumg. Jahresber. 1895.

Frank, Revue d'Hygiène. 1913.

Graham Smith, The Bacteriology of Diphtheria (Nuttall und Graham Smith, Cambridge University Press. 1913).

Glücksmann, Diese Zeitschr. 1897. Bd. XXVI.

Gerber, Berliner klin. Wochenschr. 1905. Bd. XLII. Zitiert von Graham Smith.

Gabrischewsky, Diese Zeitschr. 1901. Bd. XXXVI.

Geirsvold, Tidskrift for den Norske lägeforening. 1903. Zitiert v. Ustvedt. 
Gorham, Journ. of Med. Research. 1901. VI. Zitiert von Graham Smith. Golowkoff, Centralbl. für Bakt. 1899. Ref. Bd. XXV.

Goadby, Trans. Epidem. Soc. 1900. XIX. Zitiert von Graham Smith. von Hofmann-Wellenhof, Centralbl. für Bakt. 1887. Abt. I. Bd. II. Heubner, Klin. Studien über die Behandlung der Diphtherie mit dem Behringschen Heilserum. Leipzig 1895. Zitiert von Muysken. XXXXI.

Hasslauer, Centralbl. für Bakt. 1904. Bd. XXXII; 1906. Bd. XXXVII u.

Thure Hellström, Militair Helsowärd. 1898. Zitiert von Kober.

Hewlett und Knight, Trans. Brit. Inst. Press. Med. 1. Series. 1897. Zitiert von Graham Smith.

Johannessen, Deutsche med. Wochenschr. 1895. Bd. XXI. Zitiert von Graham Smith.

Jochmann, Lehrbuch der Infektionskrankheiten. Berlin 1914.

Kossel, Diese Zeitschr. 1894. Bd. XVII.

Kolle, Diese Zeitschr. 1895. Bd. XIX.

Kober, Diese Zeitschr. 1899. Bd. XXXI.

Loeffler, Centralbl. für Bakt. 1887. Bd. IV.

Loeffler und Abel, Deutsche med. Wochensch. 1894. Nr. 47.

Lehmann und Neumann, Mediz. Hand-Atlanten. 1907. Bd. X. II. Teil. Lesieur, Les Bacilles dit. Pseudo-Diphtheriques. Paris, Baillière 1902.

Lambotte, Centralbl. für Bakt. 1901. Abt. I. Bd. XXX.

Lippmann, Diese Zeitschr. 1910. Bd. LXVII.

Leegaard, Tidskrift for den Norske lägeforening. 1903. Zitiert von Ustvedt. Lomry, Revue d'Hyg. 1914. XXXVT. Nr. 8 bis 10.

Lambert Lack, Med. Chirurg. Trans. 1899. LXXXII. Zitiert von Pugh. Martin, Ann, de l'Inst. Pasteur. 1892. 1898.

Mallory, Pathology of Diphtheria (Nuttall und Graham Smith. 1913). Muysken, Serumtherapie gegen Diphtherie. Dissertation. Utrecht 1896. Morel, Contrib. à l'Etude de la Diphthérje. Thèse de Paris. 1891. Zitiert von Muysken.

Massachusetts State Board of Health. Zitiert von Graham Smith.

Meyer, Centralbl. für Balt. 1896. Ref. Bd. XX.

Müller, Centralbl. für Bakt. 1896. Ref. Bd. XXI.

Mark und Pollak, Hyg. Rundschau. 1914.

Mac Donald, Lancet. 1911. Nr. 4569. Ref. Ned. Tyd. oor Geneeskunde. 19II. I B.

de Negri, Bydrage tot de Kennis der Corynebacterien. Dissertation. Utrecht 1915.

Neisser, Diese Zeitschr. 1897. Bd. XXIV.

Derselbe, 7. Tagung der Freien Ver. für Mikrobiologie in Berlin. Centralbl. lür Bakt. 1913. Ref. Bd. LVII.

Newsholme, Public Health Lab. Victoria Univ. Manchester. 1904. Zitiert von Graham Smith.

Neumann, Centralbt. für Bakt. 1902. Bd. XXXI.

Derselbe, Diese Zeitschr. 1902. Bd. XL.

Nuttall und Graham Smith, Bacteriology of Diphtheria. Cambridge University Press. 1913.

Otto, Berliner klin. Wochenschr. 1910. 

Smith.

Park und Beebe, N. Y. Med. Record. 1894. XLVI. Zitiert von Graham

Prip, Diese Zeitschr. 1901. Bd. XXXVI.

Pugh, Journ of Hygiene. 1902. Vol. II.

Park, N. Y. Med. Record. 1892. Zitiert von Graham Smith.

Pech, Lancet. 1901. I. Zitiert von Lesieur.

Petrie, Journ. of Hygiene. 1905. V.

Roux und Yersin, Ann. de l'Inst. Pasteur. 1888. 1890.

Roussel und Malard, Revue d'Hygiène. 1910.

M. van Riemsdyk, Centralbl. für Bakt. 1914. Bd. LXXV.

Dieselbe, Folia Mikrobiologica. 1915. Jahrg. IV. Heft I. Vortrag, gehalten für den Niederländischen Verein für gesamte Mikrobiologie.

Ravenel, Med. News. 1895. XXVII. Zitiert von Graham Smith.

Richmond und Salter, Guys Hospital Reports. 1896. LIII. Zitiert von Graham Smith.

Ritter, Baumg. Jahresber. 1894.

Richardière und Tollemer, Presse Méd. 1899. Nr. 25. Zitiert von Lesieur.

Schanz, Diese Zeitschr. 1899. Bd. XXXII.

Spronck, Semaine Medicale. 1896.

Derselbe, Ann. de l'Inst. Pasteur. 1895 bis 1898.

Schottmüller, Deutsche med. Wochenschr. 1895. Bd. XXI.

Scheller, Centralbl. für Bakt. 1906. Bd. XL.

Derselbe, Baumg. Jahresber. 1893. Bd. IX.

Slawyk und Manicatide, Diese Zeitschr. 1898. Bd. XXIX.

Seligmann, Diese Zeitschr. 1912. Bd. LXX.

Silberschmidt, zitiert von Drigalsky.

Schäfer, Brit. Med. Joum. 1895. I. Zitiert von Graham Smith.

Schürmann, Hygienische Rundschau. 1916. Nr. 5.

Schmitz, Centralbl. f. Bakt. 1916. Bd. LXXVII.

Spirig, Diese Zeitschr. 1899. Bd. XXX.

Steenmeyer, Over den aard en de beteekenis der Corynebacterien die op den Normalen Pharynx van den Mensch voorkomen. Dissertation. Utrecht 1897.

Stadler, Hyg. Rundschau. 1909.

de Simoni, Centralbl. für Bakt. 1899. Abt. I. Bd. XXVI.

Stein, Centralbl. für Bakt. 1900. Bd. XXVIII.

Tjaden, Centralbl. für Bakt. 1907. Ref. Bd. XL.

Thomas, Brit. Med. Journ. 1904. II. Zitiert von Graham Smith.

Trump, Centralbl. für Bakt. Bd. XX.

Ustredt, Diese Zeitschr. 1906. Bd. LIV.

Welch, Centralbl. für Bakt. 1893. Bd. XVI.

Wolff, Diese Zeitschr. 1895. Bd. XIX.

Williams, Boston Med. und Surg. Journ. 1896. CXXXV. Zitiert von Graham Smith.

Wright, Studien ïber Immunisierung. Jena 1909.

Westbrook, Wilson und Mc̀ Daniel, Journ. Boston. Soc. of Med. Sc. Vol. IV. Zitiert von Graham Shmith.

Zarnico, Centralbl. für Bakt. 1889. Bd. VI, 